\title{
Chemical Speciation of the System Cu(II)-Indomethacin in Ethanol and Water by UV-Vis Spectrophotometry
}

\author{
Norma Rodríguez-Laguna, ${ }^{1}$ Luis I. Reyes-García, ${ }^{1}$ Rosario Moya-Hernández, ${ }^{1}$ \\ Alberto Rojas-Hernández, ${ }^{2}$ and Rodolfo Gómez-Balderas ${ }^{1}$ \\ ${ }^{1}$ Laboratorio de Fisicoquímica Analítica, Unidad de Investigación Multidisciplinaria, Facultad de Estudios Superiores-Cuautitlán, \\ Universidad Nacional Autónoma de México, Carretera Cuautitlán-Teoloyucan Km 2.5, San Sebastián Xhala, 54714 Cuautitlán Izcalli, \\ MEX, Mexico \\ ${ }^{2}$ Laboratorio R-105/R-107, Área de Química Analítica, Departamento de Química, División de Ciencias Básicas e Ingeniería, \\ Universidad Autónoma Metropolitana-Iztapalapa, Avenida San Rafael Atlixco 186, Colonia Vicentina, 09340 México, DF, Mexico
}

Correspondence should be addressed to Rodolfo Gómez-Balderas; rodolfo.gomez@unam.mx

Received 11 December 2015; Accepted 1 March 2016

Academic Editor: Narcis Avarvari

Copyright ( 2016 Norma Rodríguez-Laguna et al. This is an open access article distributed under the Creative Commons Attribution License, which permits unrestricted use, distribution, and reproduction in any medium, provided the original work is properly cited.

\begin{abstract}
It has been proposed that the metal-drug complexes could be in fact the active agents displaying therapeutic effects of drugs. The characterization of the global formation equilibrium of complexes formed between metal ions and species with biological activity such as nonsteroidal anti-inflammatory drugs provides essential information to understand the mechanism of action of drugs. Since equilibrium constants determine the relative predominance of species, they provide crucial information to identify what complexes are more likely to be present in the system being responsible for the therapeutic effects of the drug. In this paper, the systems formed between copper and Indomethacin of different concentrations in ethanol or water were studied by UV-Vis spectrophotometry. The stoichiometry of the complexes $\mathrm{Cu}(\mathrm{II})$-Indomethacin and their formation constants were investigated. Moreover, molecular structures of the $\mathrm{Cu}$ (II)-Indomethacin complexes were explored by means of the molecular modeling within the frame of the density functional theory.
\end{abstract}

\section{Introduction}

Nonsteroidal anti-inflammatory drugs (NSAIDs) are used as analgesic, antipyretic, and anti-inflammatory activity; they also offer therapeutic benefits in preventing some cancer types [1] and in the treatment of neurodegenerative diseases $[2,3]$; despite these important therapeutic effects, their mechanisms of action at the molecular scale are not completely understood.

Indomethacin (IndoH), molecular formula $\mathrm{C}_{19} \mathrm{H}_{16} \mathrm{ClNO}_{4}$ and chemical name 2-[1-(4-chlorobenzoyl)-5-methoxy-2methylindol-3-yl]acetic acid (Scheme 1), a member of the arylalkanoic acid family, is a nonsteroidal anti-inflammatory drug with analgesic, antipyretic, and anti-inflammatory activity [4]. It has been identified as a nonselective inhibitor drug of cyclooxygenase enzymes COX1 and COX2, which inhibits the synthesis of prostaglandins [4-9]. Its solubility in water is very low but acceptable enough to carry out UV-Vis Spectroscopy determination of some of its physicochemical properties in solution $[4,10,11]$. For instance, so far, the $\mathrm{p} K_{\mathrm{a}}$ value of the IndoH has been found by UV-Vis and density functional theory (DFT) based methods, among other approaches; these $\mathrm{p} K_{\mathrm{a}}$ values range from 4.13 to 4.52 $[10,12-14]$.

On the other hand, copper is present in around 100 enzymes in living organisms [15], the reason why it is a very important biochemical agent; there are abundant observations about altered levels of copper in various acute diseases; particularly, lack of copper is identified in illness resulting in inflammatory processes. It has been documented that the administration of compounds of NSAIDs with metal ions, especially with $\mathrm{Cu}(\mathrm{II})$, produces an enhanced therapeutic 


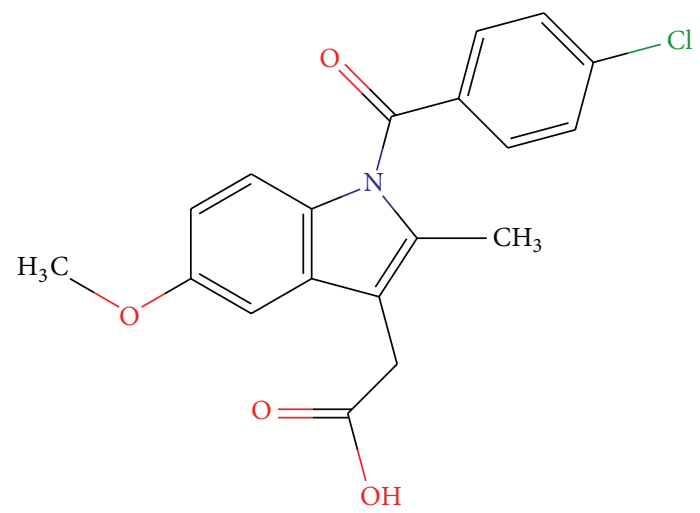

Scheme 1: Molecular structure of Indomethacin (IndoH).

action as well as less negative side effects than the parent NSAID [16, 17].

Complexes of $\mathrm{Cu}(\mathrm{II})$ and carboxylic acids exist in solution and in their crystalline forms either as monomeric or dimeric structures, although a marked preference for the formation of dimeric structures of the type of $\mathrm{Cu}(\mathrm{II})$-Acetate has been identified $[9,18-23]$. The $\mathrm{Cu}(\mathrm{II})$-Carboxylate monomers exist in a trans-configuration with unidental bis(carboxylate) bond and the metal center $\mathrm{Cu}$ (II) with a coordination number ranging from four to six [9]. On the other hand, the widely studied, dimeric compounds of $\mathrm{Cu}(\mathrm{II})$ have structures type "paddle wheel," where the $\mathrm{Cu}-\mathrm{Cu}$ bond distance is $2.64 \AA$, which marginally exceeds the distance $\mathrm{Cu}-\mathrm{Cu}$ in the metallic copper $(2.56 \AA)$ [9]. Those $\mathrm{Cu}(\mathrm{II})-\mathrm{NSAID}$ complexes, where the NSAID contains carboxylate groups, tend to have similar structures, with solvent molecules in the position trans to the $\mathrm{Cu}-\mathrm{Cu}$ bond. In such complexes, each $d^{9}$ ion donates an electron to give rise to an important metal-metal interaction shortening the $\mathrm{Cu}-\mathrm{Cu}$ distance. Interestingly, it has also been found that $\mathrm{Cu}(\mathrm{II})$-drugs dimeric complexes seem to be therapeutically more effective and less toxic than monomeric complexes, which in turn are less lipophilic and more reactive [23]. Thus, the monomeric-dimeric distribution is revealed as an important factor in the toxicity and effectiveness of the complexes. That distribution is determined by the values of equilibrium constants of different complexes, that is, by the thermodynamics of the process of formation of the stable species in solution.

Regarding the geometries adopted by the $\mathrm{Cu}(\mathrm{II})$-Indomethacin complexes, the X-ray study of the compound $\mathrm{Cu}(\mathrm{II})_{2}[\mathrm{Indo}]_{4} \mathrm{~L}_{2}\left(\mathrm{~L}=\mathrm{H}_{2} \mathrm{O}\right.$, DMSO, and DMF) has been reported [21, 22], where the characteristic known paddle wheel structure of dinuclear $\mathrm{Cu}(\mathrm{II})$-Carboxylate is present $[9,24,25]$. Important information about the formed complexes is found from the X-ray characterization, but to discuss the pharmacological action of the $\mathrm{Cu}(\mathrm{II})$-Indomethacin complexes, it is necessary to identify those species predominating under physiological conditions as they play a central role in displaying the biological effect.

As far as we know, $\mathrm{Cu}(\mathrm{II})$-Indomethacin species formed in solution either mononuclear or dinuclear have not yet been identified and/or characterized. A study of the speciation of
$\mathrm{Cu}(\mathrm{II})$-Indomethacin system in solution represents a first approach to know the distribution and formation (stability) constants of the complexes. Given the low solubility of Indomethacin in water, the UV-Visible spectrophotometry becomes a suitable technique for the speciation of the $\mathrm{Cu}(\mathrm{II})$-Indomethacin systems; in this respect, molar ratios and continuous variations methods supported on UVVisible spectrophotometry have been successfully applied for the speciation of $\mathrm{Fe}$ (III)-Tenoxicam and Fe(III)-Meloxicam solutions $[26,27]$. The determination of the structure of the crystallized complexes can be performed either by X-ray methods or by applying quantum-chemistry based methods; the applicability of theoretical methods allows the structural characterization of the species in solution. Molecular modeling based on the density functional theory helps us to know the structure of those species, in the different stoichiometries experimentally recognized in solution.

To perform the speciation study, computer programs such as TRIANG [28], SQUAD [29], and MEDUSA [30] were employed. TRIANG determines, from an arrangement of absorbances $(A)$ at different wavelengths $(\lambda)$, the most probable number of species absorbing electromagnetic radiation. The number of species that the program reports depends on the value of the error of transmittance $(\Delta T)$ that is evaluated applying the theory of error propagation on the different analytical procedures, such as preparation of solutions and error of the analytical instruments. SQUAD (Stability Quotients from Absorbance Data) created by Leggett and McBryde [29] is designed to refine equilibrium constants from a proposed chemical model (which can be dependent on or independent of the $\mathrm{pH}$ ), from absorbance data obtained at different wavelengths and different chemical composition (total concentrations of metal and ligand) of the systems. The program can be used to treat data for aqueous and nonaqueous solutions. The program employs a least square approximation using the Gauss-Newton algorithm; it calculates the values of the global formation constants that minimize the sum of residual squares $(U)$ between the experimental and calculated absorbance of the $q$ species at the $m$ wavelengths, as follows:

$$
U=\sum_{k=1}^{q} \sum_{\lambda}^{m}\left(A_{k}^{\exp (\lambda)}-A_{k}^{\mathrm{cal}(\lambda)}\right)^{2} .
$$

To determine if the proposed chemical model reproduces the experimental information, SQUAD uses the following statistical parameters: parameter of correlation, standard deviation of the absorbance data $\left(\sigma_{\text {data }}\right)$ and of the equilibrium constants $\left(\sigma_{\text {constant }}\right)$, standard deviation by spectra $\left(\sigma_{\text {spectra }}\right)$, and standard deviation of the molar absorptivity coefficients $\left(\sigma_{\text {coef }}\right) . \sigma_{\text {data }}$ indicates the validity of the proposed chemical model; for reliable data, this deviation is expected in the range from \pm 0.0001 to \pm 0.001 . The statistical analysis presented by SQUAD depends largely on the accuracy of the equipment used, the amount of data fed, and the chemical complexity of the system. Not only does the process of selecting the best chemical model rely on obtaining good statistical parameters, but also the internal consistency of the model must be checked; for example, the calculated molar 
absorptivity coefficients for each species should be consistent with its experimental behavior, revealing the predominating species under certain given experimental conditions. Finally, MEDUSA (Make Equilibrium Diagrams Using Sophisticated Algorithms) creates diagrams of distribution of the species in the system, providing their molar fractions in terms of concentrations; calculations are based on the values of the stability constants given by SQUAD.

In this paper, we study the interaction of metal copper ion with Indomethacin; looking for the stoichiometry of the $\mathrm{Cu}(\mathrm{II})$-Indomethacin species formed in solution, we employed the molar ratios and the continuous variations methods on UV-Visible spectrophotometric data. Then, we proposed a series of formation chemical equilibriums of the complexes in solution and computed their stability constants. Furthermore, the molecular structures of the identified species in solution were modeled through density functional theory methods. This contribution could be used for the design of more powerful drugs with fewer side effects to the organism. Likewise, the speciation in solution of these species can help determine the optimal conditions for drug administration.

\section{Materials and Methods}

\subsection{Experimental Section}

2.1.1. Reagents and Equipment. Indomethacin 99\% (SIGMA Life Science), copper (II) nitrate hydrate $\left(\mathrm{Cu}\left(\mathrm{NO}_{3}\right)_{2}\right.$. $x \mathrm{H}_{2} \mathrm{O}$ ) 99.999\% (ALDRICH CHEM. CO.), $\mathrm{NaOH}$ QP 98.1\% (FERMONT), and $\mathrm{HCl}$ 35.6\% (Chemistry MEYER) were employed without any further treatment. Anhydrous ethyl alcohol 99.95\% (J. T. Baker) and deionized water with $R=18.2 \mathrm{M} \Omega$ (Pureb Classic ELGA) were used to prepare ethanol or aqueous solutions. UV-Vis spectrophotometric data were recorded with a Lambda 35 Perkin-Elmer UV-Vis spectrophotometer, with Quartz cells of $1 \mathrm{~cm}$ of optical path length. A Perkin-Elmer Frontier IR/FIR was employed for the IR spectrophotometry.

\subsection{Methodology}

2.2.1. Molar Ratios. Solutions of $\mathrm{Cu}(\mathrm{II})$ and Indomethacin at the $10^{-2}, 5 \times 10^{-2}, 10^{-3}$, and $10^{-4} \mathrm{M}$ concentrations were prepared, according to the experimental design, to carry out either molar ratios or continuous variations methods [26]. The first three of those solutions were prepared with ethanol, while water was used for the concentration $10^{-4} \mathrm{M}$. The IndoH was dissolved with $\mathrm{NaOH}$ stoichiometric amount before completing the volume with ethanol or water to form the Indo ${ }^{-}$anion. Temperature was kept constant at $25^{\circ} \mathrm{C}$.

The molar ratios method allows finding the stoichiometry of the species in solution from a plot of absorbance as a function of $r$, where $r$ is the molar ratio of the titrant added with respect to the analyte. For example, $r=n_{\mathrm{Cu}(\mathrm{II})} / n_{\mathrm{Indo}^{-}}$, though it is also possible to graph in reverse; that is, $r=$ $n_{\text {Indo }}-n_{\mathrm{Cu}(\mathrm{II})}$. To perform the method, two series of systems were prepared: (1) fixing the concentration of Indo- and varying the concentration of $\mathrm{Cu}$ (II) and (2) fixing the concentration of $\mathrm{Cu}(\mathrm{II})$ and varying the concentration of Indo ${ }^{-}$. For the first case, the systems were prepared using solutions of $\mathrm{Cu}(\mathrm{II})$ and Indo $^{-}$at concentration $10^{-2} \mathrm{M}$ in ethanol, in such a way that the final concentration of Indowas constant and equal to $2 \times 10^{-3} \mathrm{M}$ through the systems, while the concentration of $\mathrm{Cu}$ (II) varied from 0 to $8 \times 10^{-3} \mathrm{M}$. For the second case, the concentration of $\mathrm{Cu}$ (II) was fixed to $2 \times 10^{-3} \mathrm{M}$ and the concentration of Indo ${ }^{-}$varied from 0 to $8 \times 10^{-3} \mathrm{M}$. Another set of experiments were also conducted using solutions of $\mathrm{Cu}(\mathrm{II})$ and Indo ${ }^{-}$of initial concentration $5 \times 10^{-2} \mathrm{M}$ in ethanol, in such a way that the component that was fixed had a concentration of $10^{-2} \mathrm{M}$ and that the concentration of the other component varied from 0 to $4 \times$ $10^{-2} \mathrm{M}$. The measured $\mathrm{pH}$ value of different systems was found in a range of $4<\mathrm{pH}<6$.

2.2.2. Continuous Variations. To confirm the results obtained with the method of molar ratios, the method of continuous variation (also known as Job's method [31, 32]) was also used. The method allows determining the stoichiometries of the complexes in solution from graphs of absorbance as a function of the molar fraction of the ligand ( $\left.X_{\mathrm{Indo}^{-}}\right)$ or metal $\left(X_{\mathrm{Cu}(\mathrm{II})}\right)$. In this case, the systems were prepared by varying continuously the mole fraction from 0 to 1 for both components with $n_{\text {Total }}=n_{\mathrm{Cu}(\mathrm{II})}+n_{\text {Indo }^{-}}$constant. Experiments were executed using solutions of $\mathrm{Cu}(\mathrm{II})$ and Indo ${ }^{-}$with initial concentrations of $10^{-3} \mathrm{M}$ in ethanol and $10^{-4} \mathrm{M}$ in water.

In both methods, we recorded the absorption spectra in the wavelength range from 200 to $900 \mathrm{~nm}$. Absorbance values obtained in the UV-Vis spectra were organized in the appropriate way to be treated with SQUAD. Assuming that the different species in solution, in the identified stoichiometries, are related by a series of simultaneous chemical equilibriums, SQUAD is able to determine the formation global constants of the complexes associated with the general equilibrium represented in the following:

$$
\begin{aligned}
& i \mathrm{Cu}^{2+}+j \text { Indo }^{-} \longleftrightarrow \mathrm{Cu}_{i} \operatorname{Indo}_{j}{ }^{(2 i-j)} \\
& \qquad \beta_{i j}=\frac{\left[\mathrm{Cu}_{i} \operatorname{Indo}_{j}^{(2 i-j)}\right]}{\left[\mathrm{Cu}^{2+}\right]^{i}\left[\operatorname{Indo}^{-}\right]^{j}},
\end{aligned}
$$

where $\mathrm{Cu}_{i} \operatorname{Indo}_{j}{ }^{(2 i-j)}$ is the complex formed from $\mathrm{Cu}(\mathrm{II})$ and Indo ${ }^{-}$with charge of $2 i-j$ and their respective values of the stoichiometric coefficients $i$ and $j$.

2.3. Theoretical Methods. To characterize the structure of the $\mathrm{Cu}(\mathrm{II})$-Indomethacin complexes in the different stoichiometries identified in solution, each complex was minimized by means of G09 suit of programs [33] in order to obtain the most stable molecular structure. Density functional theory was applied in both the minimization procedure and the frequency calculations, which were carried out to confirm that the structure is a minimum in the corresponding gas phase Potential Energy Surfaces (PES). During the minimization of the structures, the coordination sphere of $\mathrm{Cu}$ (II) was 
completed with water molecules in all the complexes. The widely used B3LYP functional was used in all calculations; it is known that B3LYP provides molecular geometries in good agreement with experimental parameters [34]; for all of the geometry optimizations, the def-SVP basis set has been employed on all the atoms $[35,36]$.

\section{Results and Discussion}

The spectra of the complexes formed between $\mathrm{Cu}$ (II) and Indomethacin are dominated by the charge transfer bands of the ligand in the UV region and by the $d$ - $d$ transitions of the metal in the visible region [23,37]. The analysis of the changes in the spectra helps to follow the formation of the complexes and the determination of their stoichiometries. Note that the use of a different anion such as $\mathrm{Cl}^{-}$instead of $\mathrm{NO}_{3}{ }^{-}$might modify the obtained results in this study, because Indomethacin is competing for gaining sites in the coordination sphere of the $\mathrm{Cu}$ (II) cation; Indomethacin affinity for copper needs to be higher enough to displace solvent molecules and/or the anion of the copper salt. In addition, different copper salts show different solubility and this might modify the availability of $\mathrm{Cu}(\mathrm{II})$ in solution impacting the $\mathrm{Cu}(\mathrm{II})$-Indomethacin formation constants.

3.1. Molar Ratios: Fixed Concentration of Indo ${ }^{-}$and Variable Concentration of $\mathrm{Cu}(\mathrm{II})$. The family of absorption spectra $A=f(\lambda, r)$, in the visible region, obtained with the molar ratios method, at fixed concentration of Indo ${ }^{-}$and variable concentration of $\mathrm{Cu}(\mathrm{II})$ in ethanol, is shown in Figure 1. A broad absorption band with a maximum at $\lambda \approx 700 \mathrm{~nm}$ assigned to a $d_{x y, y z} \rightarrow d_{x-y}{ }^{2}{ }^{2}$ transition is observed from the beginning of $\mathrm{Cu}(\mathrm{II})$ addition to the Indo- ${ }^{-}$solution, making the formation of complexes evident since Indo ${ }^{-}$solution itself does not absorb visible light. Adding more $\mathrm{Cu}(\mathrm{II})$, the absorbance of the solutions is continuously increased up to the system with $r=0.6$. Then, the maximum absorption decreases and presents a bathochromic shift from $\lambda \approx 700 \mathrm{~nm}$ to $\lambda \approx 730 \mathrm{~nm}$. The spectra corresponding to solutions in $0.6 \leq r \leq 0.75$ form an isosbestic point at $\lambda \approx 812 \mathrm{~nm}$ (see the inset in Figure 1(b)). A second isosbestic point is observed in $\lambda \approx 775 \mathrm{~nm}$ for those systems with $0.75 \leq r \leq 1.125$ (see Figure 1(c)). This behavior demonstrates the existence of at least one chemical equilibrium established between the $\mathrm{Cu}(\mathrm{II})$ and Indomethacin species. For solutions with $r>$ 1.125 , the maximum presents a bathochromic shift to $\lambda \approx$ $785 \mathrm{~nm}$, where the absorption of the Jahn-Teller-distorted free copper ion is registered and gradually increases with the excess of $\mathrm{Cu}$ (II) in the system.

Now, applying TRIANG to determine the number of absorbing species, with the value of transmittance error in the range $0.0008 \leq \Delta T \leq 0.002$, it predicts the existence of three absorbing complexes. Figure 2 shows the plot of absorbance as a function of the molar ratio at $\lambda=705 \mathrm{~nm}$, $A^{705}=f(r)$, where $r=n_{\mathrm{Cu}(\mathrm{II})} / n_{\mathrm{Indo}^{-}}$. It is worth noting that about $r=0.5$, where the formation of neutral complex $1: 2$ (Cu(II) : Indomethacin) is expected, a light turbidity was observed in the solutions, and the marked change of slope in this region would evidence the formation of species with stoichiometry $1: 2$. A second change of slope is then observed in $r=1.0$, which corresponds to the complex of stoichiometry $2: 2$ (or $1: 1$ ). Given the concentration of the $\mathrm{Cu}(\mathrm{II})$ ion, it seems that the formation of dinuclear species is favored as it has been suggested in $[38,39]$. In addition, when formation of dinuclear species is assumed for running SQUAD, the statistic parameters are better than those found assuming that mononuclear species are formed, as it will be discussed later. The last change of slope for this system is observed in $r=2.0$ (in the stoichiometry $2: 1$ ). Thus, it is noted that, having fixed the Indo ${ }^{-}$concentration in all systems and adding $\mathrm{Cu}(\mathrm{II})$, the complexes $1: 2,2: 2$, and $2: 1$ are formed, that is, $\mathrm{CuIndo}_{2}, \mathrm{Cu}_{2} \mathrm{Indo}_{2}{ }^{2+}$, and $\mathrm{Cu}_{2} \mathrm{Indo}^{3+}$.

Performing the molar ratios method but now using solutions of $\mathrm{Cu}(\mathrm{II})$ and Indo $^{-}$in ethanol, with initial concentrations of $5 \times 10^{-2} \mathrm{M}$, the $A=f(\lambda, r)$ and $A^{705}=f(r)$ curves show the same behavior of the graphics in Figures 1 and 2 , respectively, which confirms the stoichiometries already obtained.

\subsection{Molar Ratios: Fixed Concentration of $\mathrm{Cu}(\mathrm{II})$ and Variable} Concentration of Indo $^{-}$. The method of molar ratios was carried out conversely with $\mathrm{Cu}$ (II) concentration fixed to $2 \times$ $10^{-3} \mathrm{M}$ in all the systems, but with Indo $^{-}$concentrations varying from 0 to $8 \times 10^{-3} \mathrm{M}$. Figure 3 displays only the absorbance spectra, $A=f(\lambda, r)$, for those systems with $0 \leq r \leq 1.5$, because systems with $1.5<r \leq 4$ showed a precipitate; thus, they do not provide useful spectroscopic data for further analysis. Figure 3 shows that the first system with $r=n_{\text {Indo }}-/ n_{\mathrm{Cu}(\mathrm{II})}=0$ which has only $\mathrm{Cu}(\mathrm{II})$ has a maximum of absorbance at $\lambda \approx 795 \mathrm{~nm}$. Since the first addition of Indo $^{-}$, the absorbance of the system continuously increases with a hypsochromic shift up to $\lambda \approx 705 \mathrm{~nm}$, where the corresponding system presents a molar ratio of $n_{\text {Indo }}-/ n_{\mathrm{Cu}(\mathrm{II})}$ equal to 1.5 , which demonstrates the formation of at least one $\mathrm{Cu}(\mathrm{II})$-Indomethacin complex.

The graph of $A^{705}=f(r)$, where $r=n_{\text {Indo }^{-}} / n_{\mathrm{Cu}(\mathrm{II})}$, is presented in Figure 4, showing 2 intersections of the straight lines at $r=0.5$ and $r=1.0$, implying that $\mathrm{Cu}(\mathrm{II})$-Indomethacin complexes formed have the stoichiometries 2:1 and 2:2, $\mathrm{Cu}_{2}$ Indo $^{3+}$ and $\mathrm{Cu}_{2} \mathrm{Indo}_{2}{ }^{2+}$. For $r \geq 1.5$, specifically in $r=2$, the complex with stoichiometry $2: 4\left(\mathrm{Cu}_{2} \mathrm{Indo}_{4}\right)$ could be formed and would explain the observed precipitate.

Now, by using the TRIANG with a transmittance error of $0.002 \leq \Delta T \leq 0.01$, it is found that there are two absorbing species in the $\mathrm{Cu}(\mathrm{II})$-Indomethacin systems; thus, the formation of the complex with stoichiometries $2: 1$ and $2: 2$ is confirmed as shown in the graph of $A=f(r)$ in Figure 4.

By performing a similar experiment in ethanol, but now with initial concentrations of $\mathrm{Cu}(\mathrm{II})$ and Indo $^{-}$equal to $5 \times$ $10^{-2} \mathrm{M}$, the graphics of $A=f(\lambda, r)$ and $A=f(r)$ were obtained; they show the same behavior observed in Figures 3 and 4, confirming the stoichiometries obtained in the previous experiment.

Regarding the precipitate observed specifically in $r=2$, the complex with $2: 4$ stoichiometry $\left(\mathrm{Cu}_{2} \mathrm{Indo}_{4}\right)$ was suggested to be formed. For qualitative purposes, the X-ray 

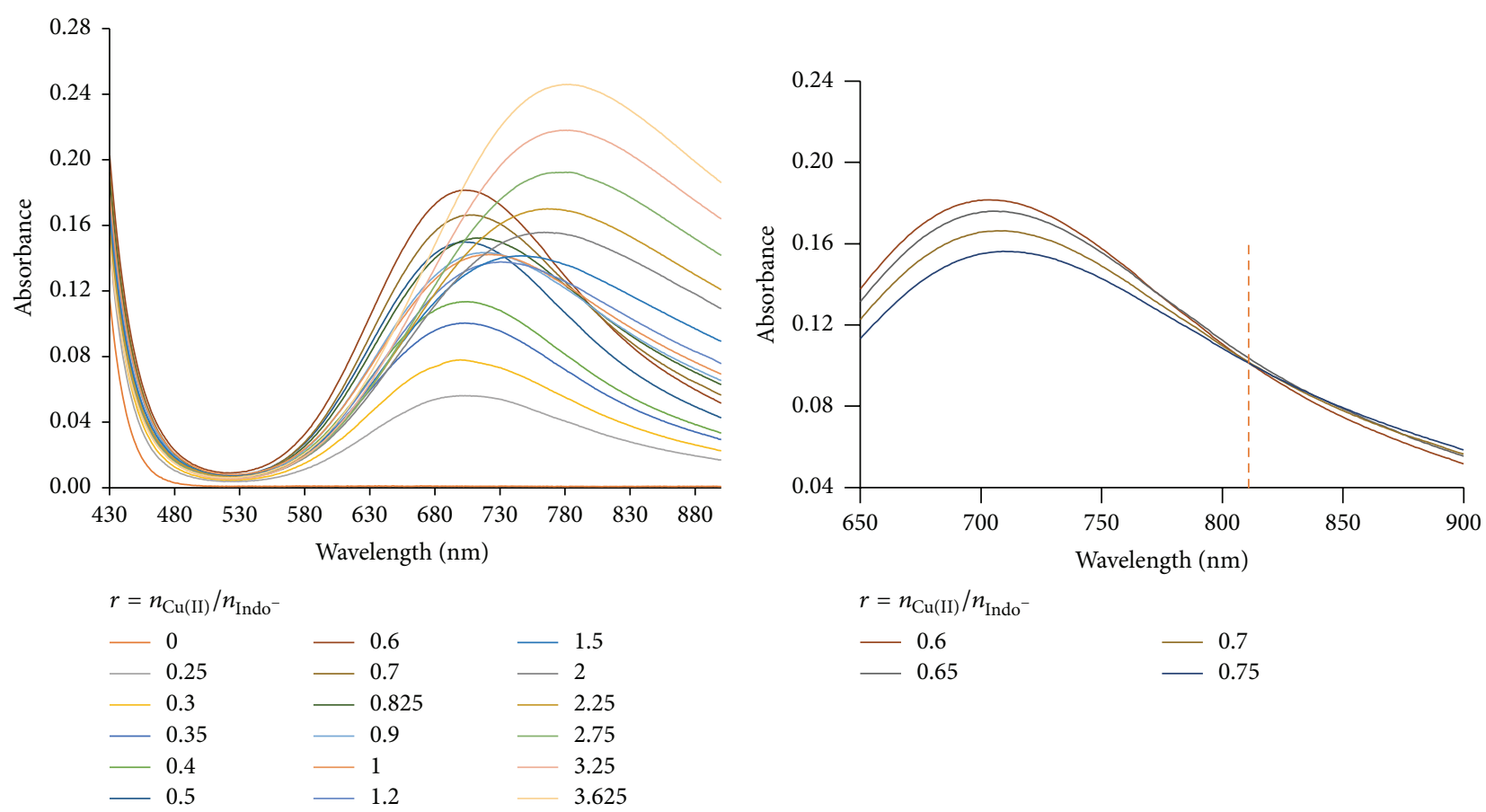

(a)

(b)

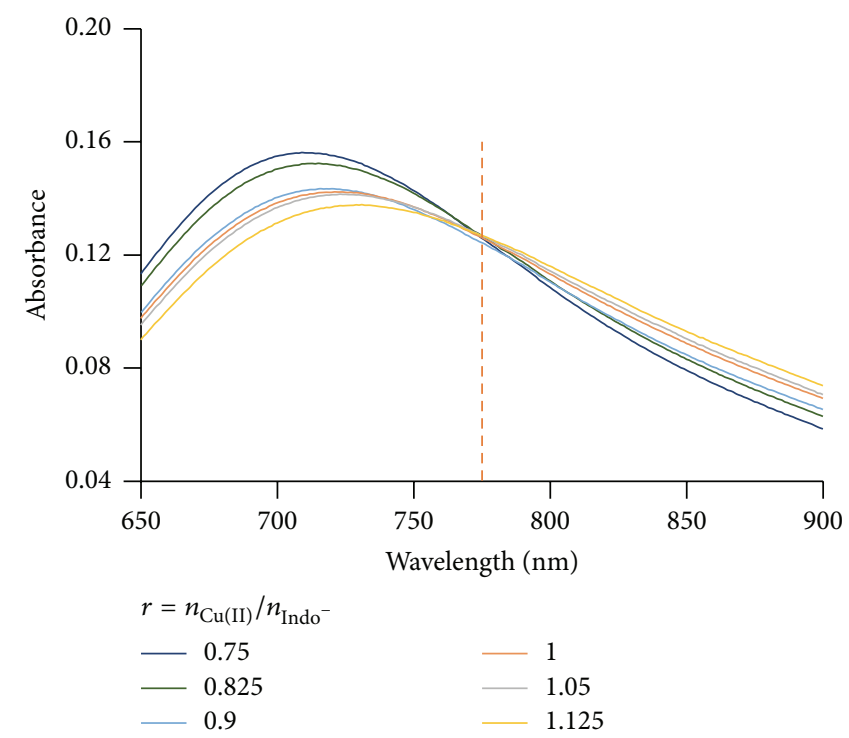

(c)

FIGURE 1: (a) UV-Vis spectra of $\mathrm{Cu}(\mathrm{II})-$ Indomethacin in ethanol applying the molar ratio method with fixed concentration of Indo ${ }^{-}$and variable concentration of $\mathrm{Cu}$ (II). (b) Isosbestic point at $\lambda \approx 812$. (c) Isosbestic point at $\lambda \approx 775 \mathrm{~nm}$.

powder diffraction pattern in the range of $2^{\circ} \leq 2 \theta \leq 30^{\circ}$ was obtained and compared with that published in [21] for $\mathrm{Cu}_{2} \mathrm{Indo}_{4}\left(\mathrm{H}_{2} \mathrm{O}\right)_{2}$ (Figure 5). Comparison shows that both compounds are isostructural and the three peaks for $2 \theta<$ $15^{\circ}$ match reasonably well. The small differences for $2 \theta>$ $15^{\circ}$ might arise from the different water/ethanol solvent of crystallization in the two samples. Additionally, the IR spectra of solid Indomethacin and the $\mathrm{Cu}_{2} \mathrm{Indo}_{4}$ precipitate were recorded (see Figure 6). The main difference is found in the asymmetric stretching $v_{\text {asym }}(\mathrm{COO})$ of the carboxylate band, which is shifted to higher frequencies; it goes from 1690 to $1629 \mathrm{~cm}^{-1}$ in Indomethacin and in the complex, respectively. The $1629 \mathrm{~cm}^{-1}$ is comparable to the $1630 \mathrm{~cm}^{-1}$ reported in [21] for $\mathrm{Cu}_{2} \mathrm{Indo}_{4}\left(\mathrm{H}_{2} \mathrm{O}\right)_{2}$, which indicates that the precipitate is a $\mathrm{Cu}(\mathrm{II})$ type dimer.

3.3. Continuous Variations: Ethanol. Figure 7 shows the absorption spectra of $A=f\left(\lambda, X_{\text {Indo }^{-}}\right)$using the method of continuous variation for the solutions in ethanol, at the concentrations of $\mathrm{Cu}$ (II) and Indo of $10^{-3} \mathrm{M} . X_{\text {Indo }^{-}}=0$ 


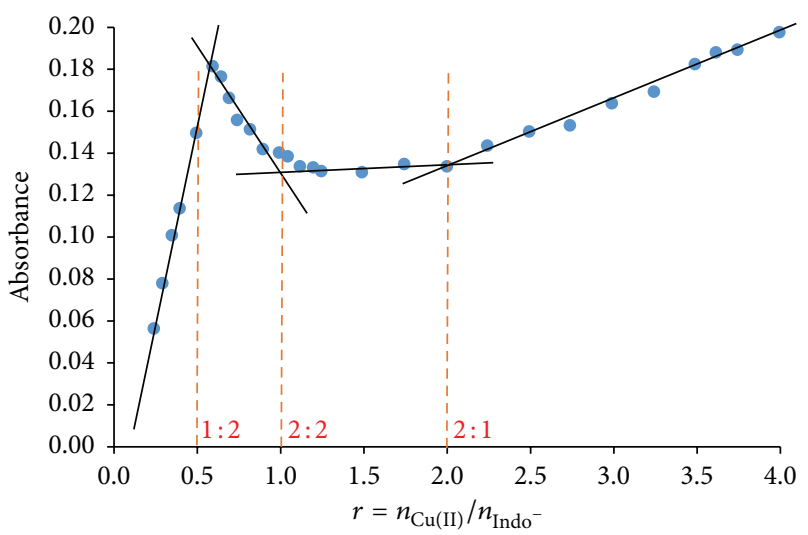

FIGURE 2: $A^{705}=f(r)$ graph: intersections in $r=0.5,1.0$, and 2.0 correspond to $\mathrm{CuIndo}_{2}, \mathrm{Cu}_{2} \mathrm{Indo}_{2}{ }^{2+}$, and $\mathrm{Cu}_{2} \mathrm{Indo}^{3+}$, respectively.
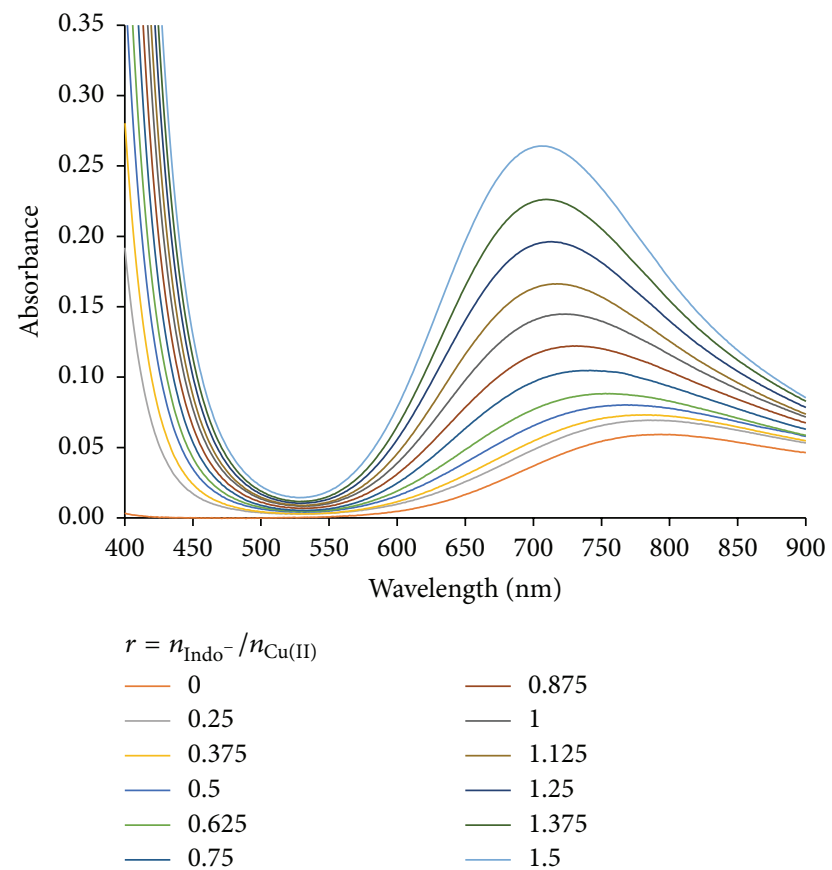

FIGURE 3: UV-Vis spectra of $\mathrm{Cu}(\mathrm{II})$-Indomethacin in ethanol applying the molar ratio method with fixed concentration of $\mathrm{Cu}$ (II) and variable concentration of Indo ${ }^{-}$.

corresponds to the initial system of $\mathrm{Cu}(\mathrm{II})$, and $X_{\mathrm{Indo}^{-}}=1$ is the initial solution of Indo- ${ }^{-}$. For best viewing, Figure 6(a) shows the spectra for the systems within $0 \leq X_{\text {Indo }^{-}} \leq 0.650$ and Figure 6(b) shows the spectra for systems in the range $0.650 \leq X_{\text {Indo }^{-}} \leq 1.0$. In Figure $7(\mathrm{a})$, the system with $X_{\text {Indo }^{-}}=0$ presents maximum absorption at $\lambda \approx 795 \mathrm{~nm}$. As the mole fraction of Indo ${ }^{-}$is increased, the mole fraction of $\mathrm{Cu}(\mathrm{II})$ is decreased and two different behaviors in the absorption spectra are observed. First, from $X_{\text {Indo }^{-}}=0$ to $X_{\text {Indo }^{-}}=0.248$, the maximum of absorbance decreases as $X_{\text {Indo }}{ }^{-}$increases. Second, for the systems with $X_{\text {Indo }}$ between 0.348 and 0.650 , the maximum of absorbance increases presenting hypsochromic displacement from 780 to $705 \mathrm{~nm}$. Furthermore, an isosbestic point is observed at $\lambda \approx 850 \mathrm{~nm}$,

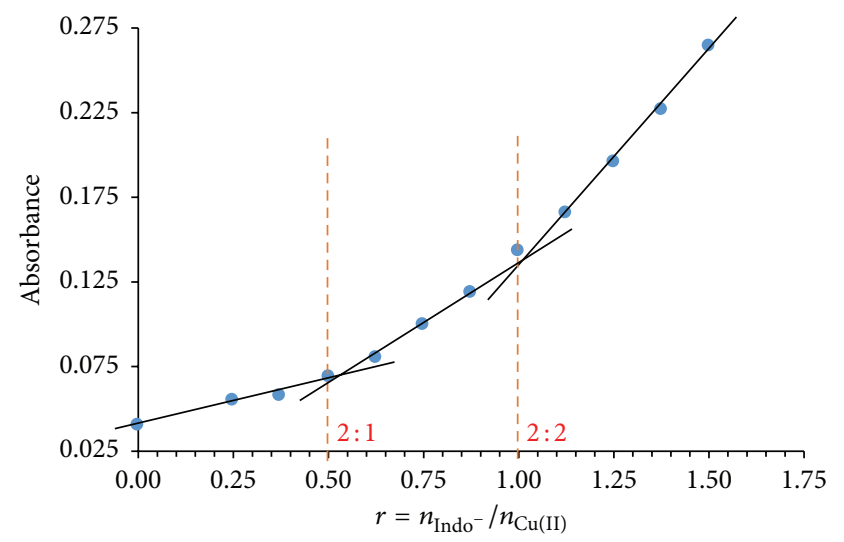

FIGURE 4: $A^{705}=f(r)$ graph: intersections of straight lines are given in values of $r$ equal to 0.5 and 1.0 that correspond to the $\mathrm{Cu}_{2} \mathrm{Indo}^{3+}$ and $\mathrm{Cu}_{2} \mathrm{Indo}_{2}{ }^{2+}$ complexes, respectively.

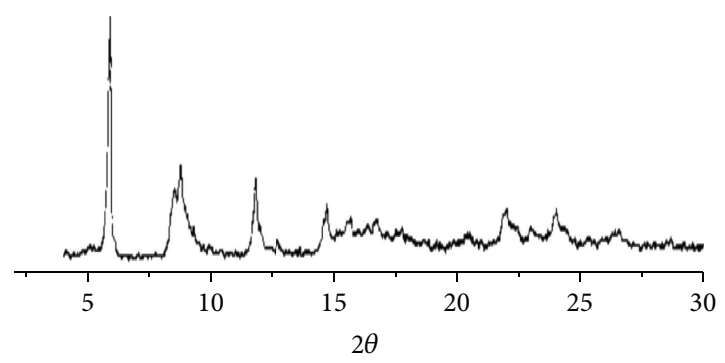

(a)

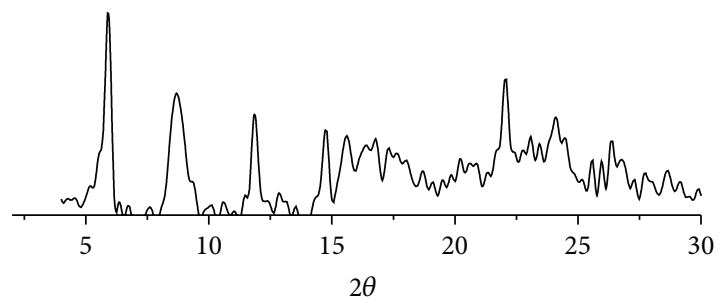

(b)

Figure 5: X-ray powder diffraction patterns of (a) $\mathrm{Cu}_{2} \operatorname{Indo}_{4}\left(\mathrm{H}_{2} \mathrm{O}\right)_{2}$ reported in [21] and (b) the precipitate in the stoichiometry $2: 4$ $\left(\mathrm{Cu}_{2} \mathrm{Indo}_{4}\right)$.

which indicates that at least one chemical equilibrium is established between $\mathrm{Cu}(\mathrm{II})$ and Indo ${ }^{-}$.

Figure 7(b) shows the absorption spectra for values of $0.650 \leq X_{\text {Indo }^{-}} \leq 0.950$. Here, the maximum of absorbance is centered on $705 \mathrm{~nm}$ and remains the same for all these systems. The system with $X_{\text {Indo }^{-}}=1$ is also shown; in this region of the electromagnetic spectrum, Indo ${ }^{-}$does not absorb light.

Figure 8 shows the $A^{705}=f\left(X_{\text {Indo }^{-}}\right)$graph at a wavelength of $705 \mathrm{~nm}$. It is observed that the experimental data can be adjusted to four straight lines. The crossings of them are located at $X_{\text {Indo }^{-}}$of $0.33,0.50$, and 0.66 . In $X_{\text {Indo }^{-}}=0.33$, the formation of the complex $2: 1$ would be expected, but due to the low concentration of $\mathrm{Cu}(\mathrm{II})$ and Indo ${ }^{-}$of $6.565 \times 10^{-4}$ and $3.535 \times 10^{-4} \mathrm{M}$, respectively, it is unlikely that $\mathrm{Cu}$ (II) forms 
TABLE 1: Logarithms of the global formation constants, $\log \beta_{i j}$, with their standard deviations $\sigma_{\text {constant }}$, as well as the statistical parameters $\sigma_{\text {data }}$ and $U$ of the $\mathrm{Cu}(\mathrm{II})$-Indomethacin complexes determined in water or ethanol.

\begin{tabular}{lcccccr}
\hline \multicolumn{2}{c}{ Complex } & $\log \beta_{i j}$ & $\sigma_{\text {constant }}$ & $\sigma_{\text {data }}$ & $U$ & Solvent \\
\hline $1: 2$ & $\mathrm{CuIndo}_{2}$ & 14.0552 & 0.4329 & & & Ethanol \\
$2: 1$ & $\mathrm{Cu}_{2} \mathrm{Indo}^{3+}$ & 9.3790 & 0.0516 & $6.0050 \times 10^{-3}$ & $2.9749 \times 10^{-2}$ & \\
$2: 2$ & $\mathrm{Cu}_{2} \mathrm{Indo}_{2}{ }^{2+}$ & 16.7165 & 0.4419 & & & \\
$1: 1$ & $\mathrm{CuIndo}^{+}$ & 6.8345 & 0.0802 & $3.5658 \times 10^{-3}$ & $1.0146 \times 10^{-2}$ & Water \\
\hline
\end{tabular}

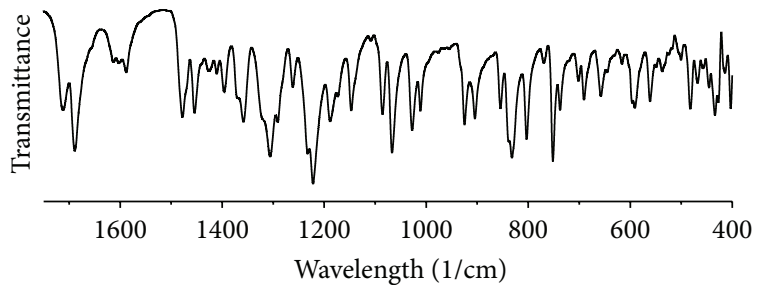

(a)

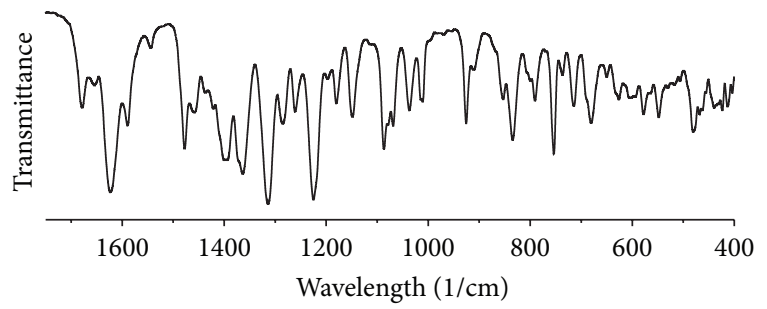

(b)

FIGURE 6: Solid state IR spectra of (a) Indomethacin and (b) the precipitate in the stoichiometry $2: 4\left(\mathrm{Cu}_{2} \mathrm{Indo}_{4}\right)$.

dimers. Thus, this intersection is indicative of the excess of $\mathrm{Cu}$ (II) and reflects the beginning of the formation of the $1: 1$ complex. Then, for $X_{\text {Indo }^{-}}=0.5$ and 0.66 , the complexes $1: 1$ and $1: 2$ are formed, that is, $\mathrm{CuIndo}^{+}$and $\mathrm{CuIndo}_{2}$. Total concentrations of $\mathrm{Cu}(\mathrm{II})$ and $\mathrm{Indo}^{-}$in the system where the $\mathrm{CuIndo}^{+}$complex is formed are both $5.05 \times 10^{-4} \mathrm{M}$, whereas the total concentrations of $\mathrm{Cu}$ (II) and Indo $^{-}$, in the system where the formation of $\mathrm{CuIndo}_{2}$ complex is observed, are $3.535 \times 10^{-4}$ and $6.565 \times 10^{-4} \mathrm{M}$, respectively.

Using a range of error transmittance of $0.001 \leq \Delta T \leq 0.01$ to run TRIANG, it is found that the number of species that absorb electromagnetic radiation is 2 , reinforcing that two complexes are formed, as previously discussed.

3.4. Continuous Variations: Water. In Figure 9 for the sake of clarity only some of the recorded absorption spectra are shown with different value of $X_{\mathrm{Indo}^{-}}$, following the continuous variation method. Here, the $\mathrm{Cu}(\mathrm{II})$ and $\mathrm{Indo}^{-}$ initial concentrations in water are $10^{-4} \mathrm{M}$. The system with $X_{\text {Indo }^{-}}=0$ is the pure $\mathrm{Cu}(\mathrm{II})$ solution; the last system with $X_{\text {Indo }^{-}}=1$ is the pure Indo ${ }^{-}$solution. At such low concentration, the changes of the spectra are followed in the UV region; as $X_{\text {Indo- }^{-}}$increases in the system, the absorption bands are more intense.
Figure 10 displays the behavior of $A^{335}=f\left(X_{\text {Indo }^{-}}\right)$; experimental data fit two straight lines with an intersection at $X_{\text {Indo }^{-}}=0.5$. At this value, the complex $1: 1\left(\mathrm{CuIndo}^{+}\right)$is formed. Note that the concentrations of $\mathrm{Cu}(\mathrm{II})$ and $\mathrm{Indo}^{-}$in the mixture are equal to $5 \times 10^{-5} \mathrm{M}$.

Once the stoichiometry of the complexes has been obtained, their global formation constants can be determined by applying the computer program SQUAD; the chemical model of the system would include the formation of the species CuIndo ${ }^{+}, \mathrm{CuIndo}_{2}, \mathrm{Cu}_{2} \mathrm{Indo}^{3+}$, and $\mathrm{Cu}_{2} \mathrm{Indo}_{2}{ }^{2+}$. Results of the global formation constants $(\log \beta)$ of the complexes $\mathrm{Cu}(\mathrm{II})$-Indomethacin are compiled in Table 1 . The $\log \beta$ values of $\mathrm{CuIndo}_{2}, \mathrm{Cu}_{2} \mathrm{Indo}^{3+}$, and $\mathrm{Cu}_{2} \mathrm{Indo}_{2}{ }^{2+}$ were obtained using the family of spectra in Figure 1; a set of 22 spectra was fed in a range of wavelength between 540 and $900 \mathrm{~nm} . \log \beta$ of the CuIndo ${ }^{+}$complex was determined using the family of spectra of Figure 9; for doing so, 18 spectra from 220 to $355 \mathrm{~nm}$ were fed.

To confirm the results of SQUAD, it is desirable to build the theoretical absorption spectra; they must fit the experimental spectra well. The theoretical values of the absorbance can be derived from applying the Beer-Lambert's law, using the molar absorptivity coefficients $(\varepsilon)$ for species predicted by SQUAD. Then, the concentration of each species $\left(C_{X}\right)$ is determined by constructing a species distribution diagram by means of MEDUSA [30], feeding the program with the values of the equilibrium constants refined by SQUAD. MEDUSA provides the mole fractions of the species present in the system, which are then used to determine the corresponding concentrations. With the values of $\varepsilon$ and $C_{X}$ and the optical pass length, the absorbance values are calculated at different wavelengths. Finally, the theoretical absorption spectra are constructed; if these fit the experimental data well, the values of the constants of equilibrium that refines SQUAD are validated.

The experiment where the concentration of Indo $^{-}$ remains fixed to $2 \times 10^{-3} \mathrm{M}$ and the concentration of $\mathrm{Cu}$ (II) varies (Figure 1) was chosen to illustrate the reconstruction of the spectra from the SQUAD-calculated formation constants. Figure 11 shows the diagram of distribution of species; the formation of $\mathrm{CuIndo}_{2}$ can be observed just after a small amount of $\mathrm{Cu}$ (II) is added to Indo ${ }^{-}$. When $\mathrm{Cu}$ (II) is added in an amount equal to half of the amount of Indo $^{-}$, the mole fraction of $\mathrm{CuIndo}_{2}$ decreases, and at the same time $\mathrm{Cu}_{2} \mathrm{Indo}_{2}{ }^{2+}$ and $\mathrm{Cu}_{2} \mathrm{Indo}^{3+}$ species begin to be formed; at this point, the relative predominance of the species is $\mathrm{CuIndo}_{2}>$ $\mathrm{Cu}_{2} \mathrm{Indo}_{2}{ }^{2+}>\mathrm{Cu}_{2} \mathrm{Indo}^{3+}$. Subsequently, when an amount of $\mathrm{Cu}(\mathrm{II})$ is equal to the Indo ${ }^{-}$, the $\mathrm{Cu}_{2} \mathrm{Indo}_{2}{ }^{2+}$ and $\mathrm{Cu}_{2} \mathrm{Indo}^{3+}$ 


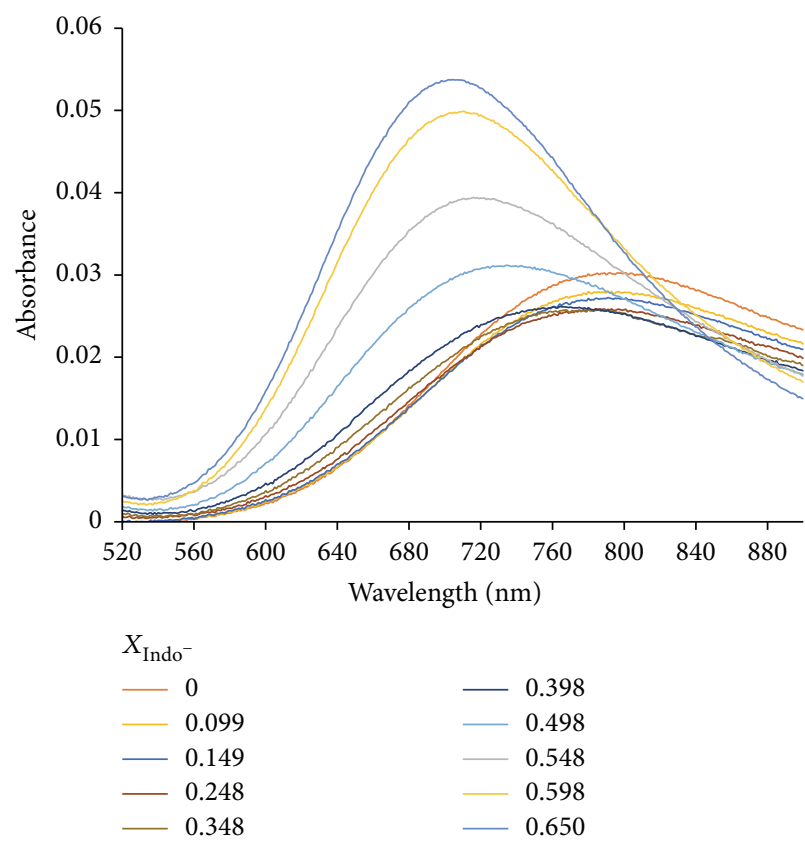

(a)

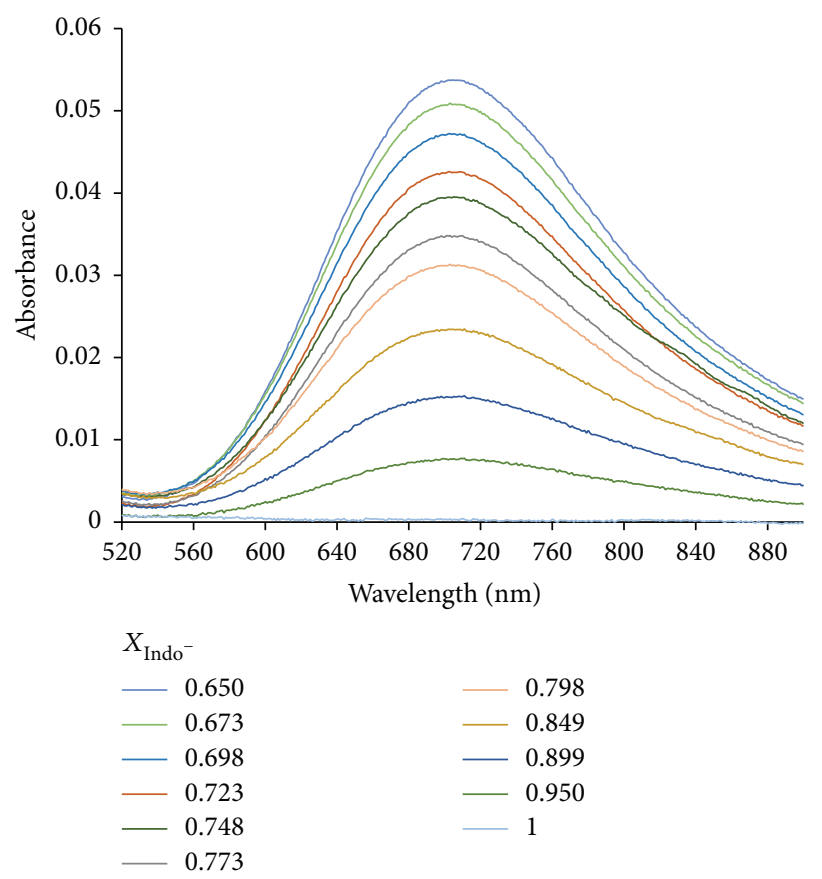

(b)

FIGURE 7: UV-Vis spectra of $\mathrm{Cu}(\mathrm{II})$-Indomethacin in ethanol using the continuous variation method. (a) Absorption spectra for systems with $0 \leq X_{\text {Indo }^{-}} \leq 0.650$. (b) Absorption spectra for systems with $0.650 \leq X_{\text {Indo }^{-}} \leq 1.0$.

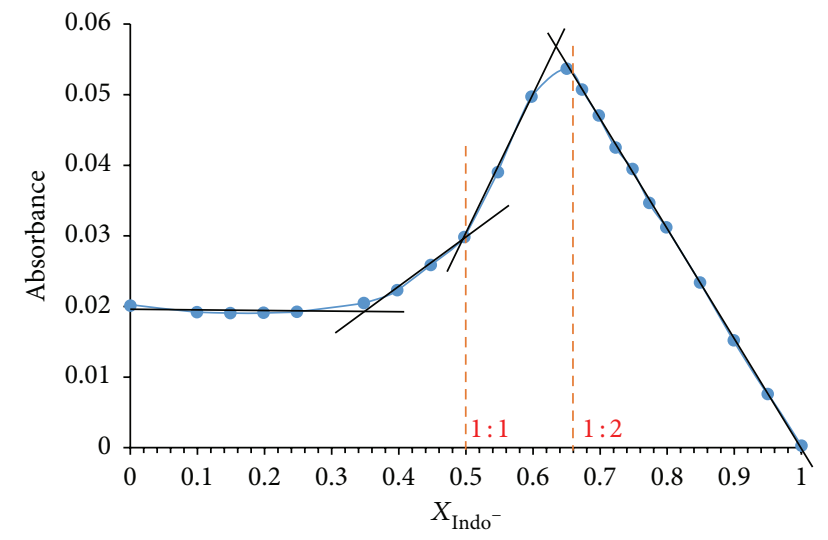

Figure 8: The $X_{\text {Indo }^{-}}=0.50$ and 0.66 indicate the formation of $\mathrm{CuIndo}^{+}$and $\mathrm{CuIndo} \mathrm{O}_{2}$ species.

complexes have the same mole fraction and, in consequence, the same concentration, while $\mathrm{CuIndo}_{2}$ begins to decline significantly.

The molar absorptivity coefficients of $\mathrm{Cu}_{2} \mathrm{Indo}^{3+}$, $\mathrm{Cu}_{2} \mathrm{Indo}_{2}{ }^{2+}$, and $\mathrm{CuIndo}_{2}$ calculated by SQUAD are shown in Figure 12; the molar absorptivity coefficient of $\mathrm{Cu}$ (II) is also shown, since this ion is also absorbed in the visible region.

Finally, Figure 13 illustrates that the theoretical spectra (continuous line) calculated with the data provided by SQUAD fit the experimental data (markers) well; this confirms that the proposed species in solution and their
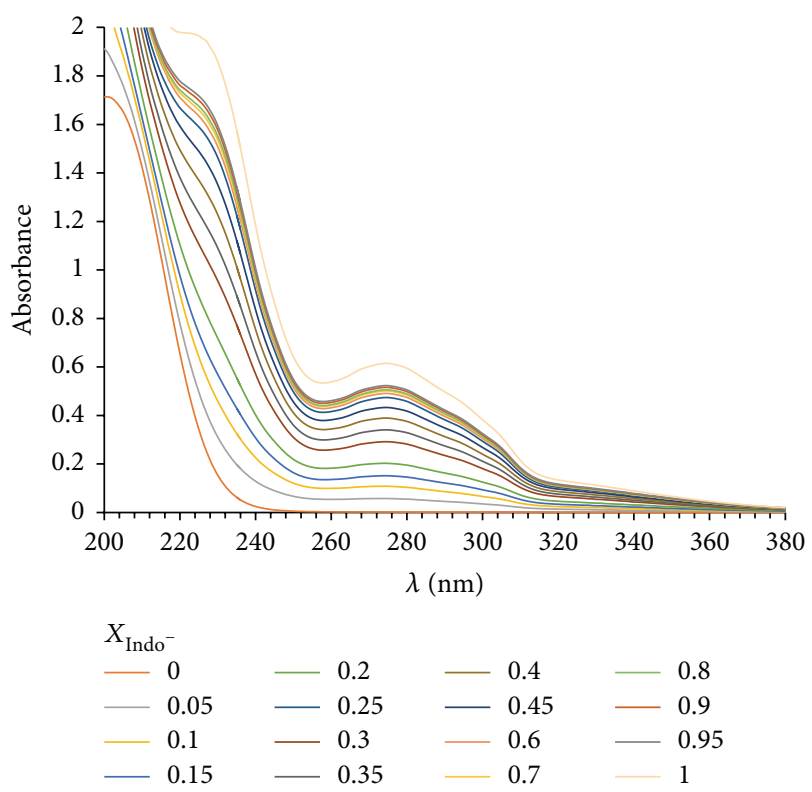

FIGURE 9: Absorption spectra for $\mathrm{Cu}(\mathrm{II})$-Indomethacin in water using the continuous variations method.

formation constants as determined by SQUAD for the $\mathrm{Cu}(\mathrm{II})$ Indomethacin system are correct.

3.5. Molecular Structure Models. The molecular structures of the $\mathrm{Cu}$ (II)-Indomethacin species formed in solution were characterized by means of theoretical calculations in gas 


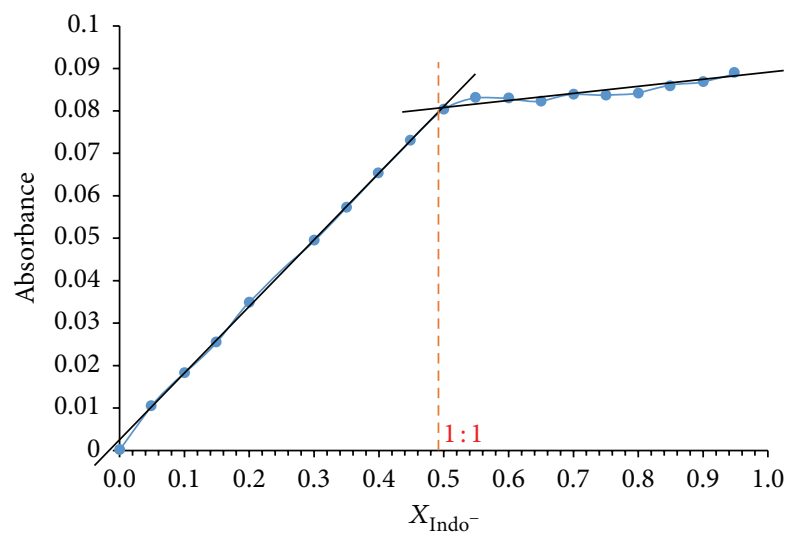

Figure 10: $A^{335}=f\left(X_{\text {Indo }^{-}}\right)$graph. In $X_{\text {Indo }^{-}}=0.5$, the complex with stoichiometry $1: 1\left(\mathrm{CuIndo}^{+}\right)$is formed.

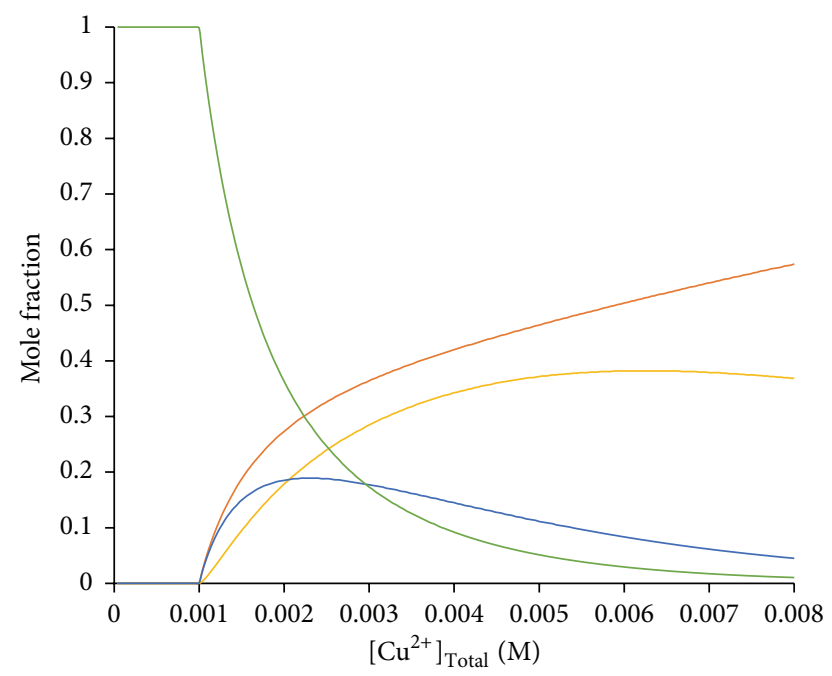

FIgURE 11: Species distribution diagram of the system $\mathrm{Cu}$ (II)Indomethacin in ethanol, the formation constants are shown in Table 1.

phase to reduce computational costs, obtaining the chelation by the Indo- ligand with $\mathrm{Cu}(\mathrm{II})$ ion as shown in Figure 14.

Molecule models in the stoichiometry 1:1 with 2, 3, and 4 water molecules in the first sphere of coordination of $\mathrm{Cu}$ (II) were optimized, resulting in the fact that the only molecule with a square geometry for $\mathrm{Cu}(\mathrm{II})$ is $\left[\mathrm{CuIndo}\left(\mathrm{H}_{2} \mathrm{O}\right)_{2}\right]^{+}$, the angle between the atoms of $\mathrm{O}-\mathrm{C}-\mathrm{O}$ of the carboxylate is $118.79^{\circ}$, and the angle between ring planes (indole and chlorobenzene) is $47.98^{\circ}$ (Figure $14(\mathrm{a})$ ).

The dinuclear complex with stoichiometry 2:1 was modeled with 2 molecules of water in the stoichiometry $\left[\mathrm{Cu}_{2} \text { Indo }\left(\mathrm{H}_{2} \mathrm{O}\right)_{4}\right]^{3+}$ resulting in a square planar geometry for one of the copper centers and a seesaw with 4 atoms around to the other $\mathrm{Cu}(\mathrm{II})$ atom; the $\mathrm{Cu}(\mathrm{II})-\mathrm{Cu}(\mathrm{II})$ bond distance is $2.72 \AA$, the angle between the atoms of $\mathrm{O}-\mathrm{C}-\mathrm{O}$ of the
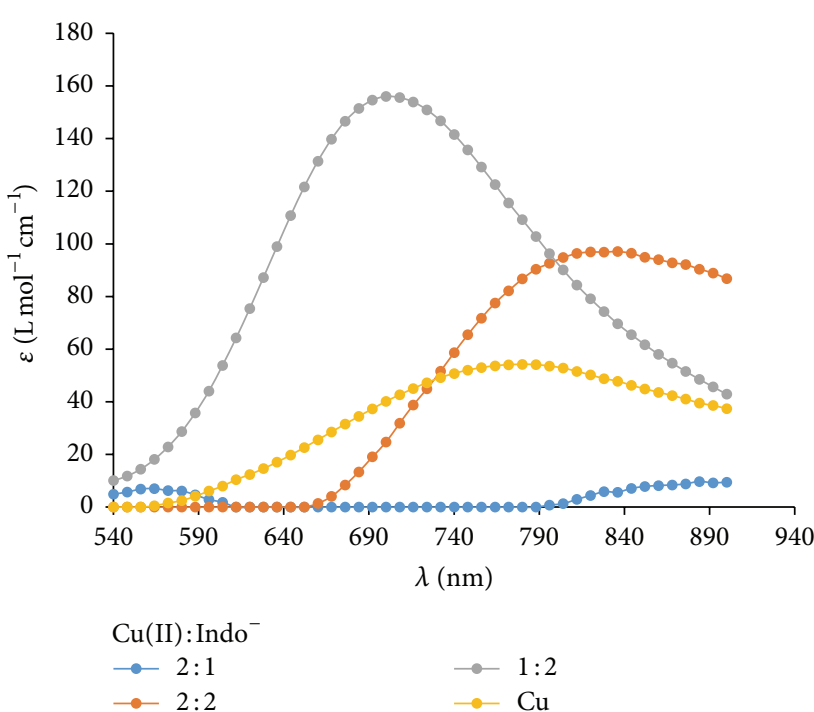

FIgURE 12: Molar absorptivity coefficients for the $\mathrm{Cu}(\mathrm{II})$ Indomethacin complexes calculated by SQUAD.

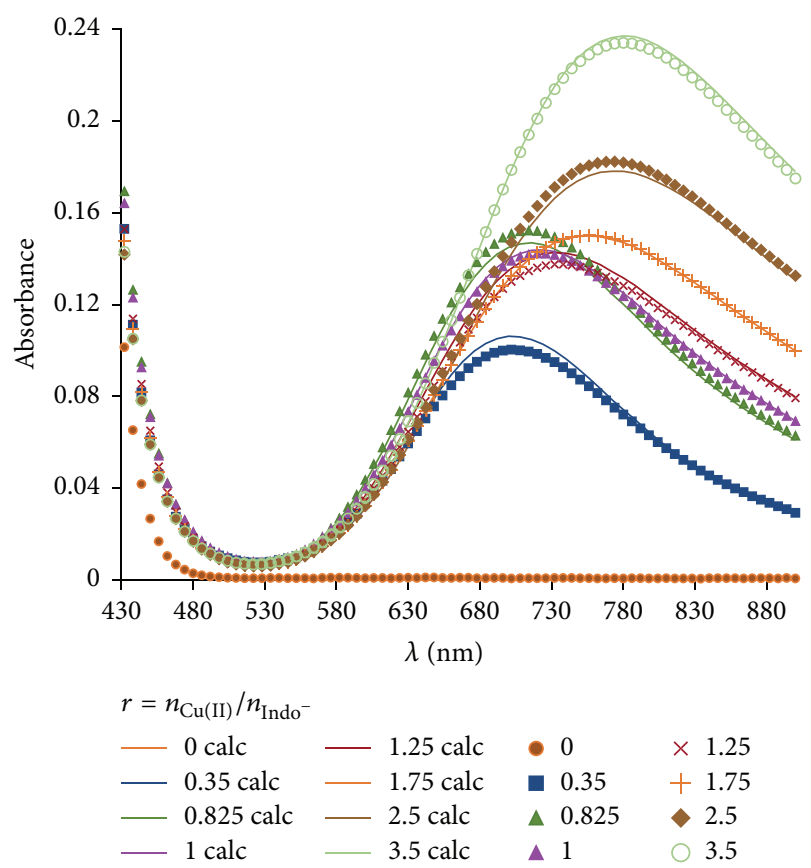

FIGURE 13: Comparison of the experimental spectra (markers) and those calculated (calc) from the formation constants refined with the SQUAD.

carboxylate is $125.29^{\circ}$, and the angle between planes is $50.27^{\circ}$ (Figure 14(b)).

The molecular structure that was determined for the complex with stoichiometry $2: 2,\left[\mathrm{Cu}_{2} \operatorname{Indo}_{2}\left(\mathrm{H}_{2} \mathrm{O}\right)_{2}\right]^{2+}$, presented a square geometry for each of $\mathrm{Cu}$ (II) atoms in the same plane; the first coordination sphere is completed with two water molecules in such a way that each one of them joins a $\mathrm{Cu}$ (II) atom. The angles between $\mathrm{O}-\mathrm{C}-\mathrm{O}$ atoms of the 2 carboxylates are $124.91^{\circ}$, and the average angle between planes of both Indomethacin ligands is $49.72^{\circ}$ (Figure $14(\mathrm{c})$ ). 


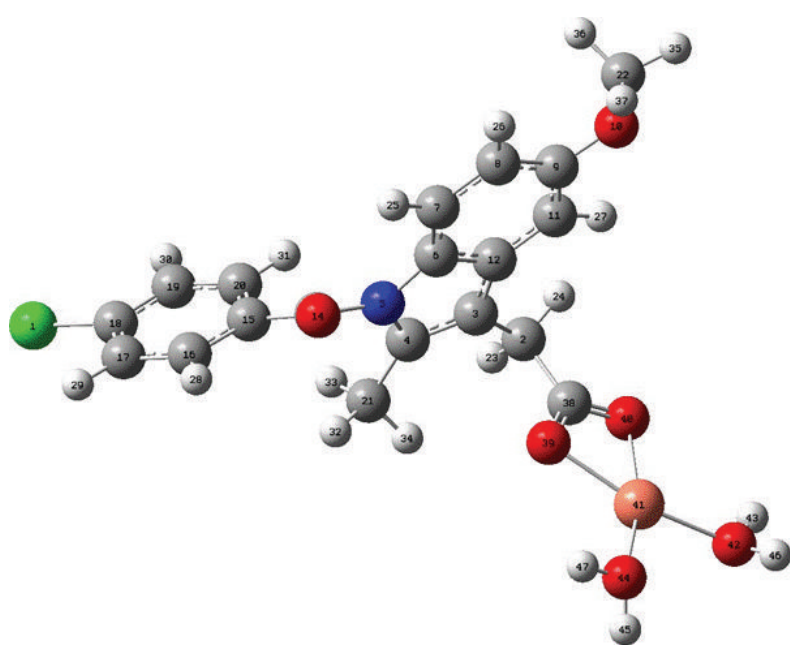

(a)

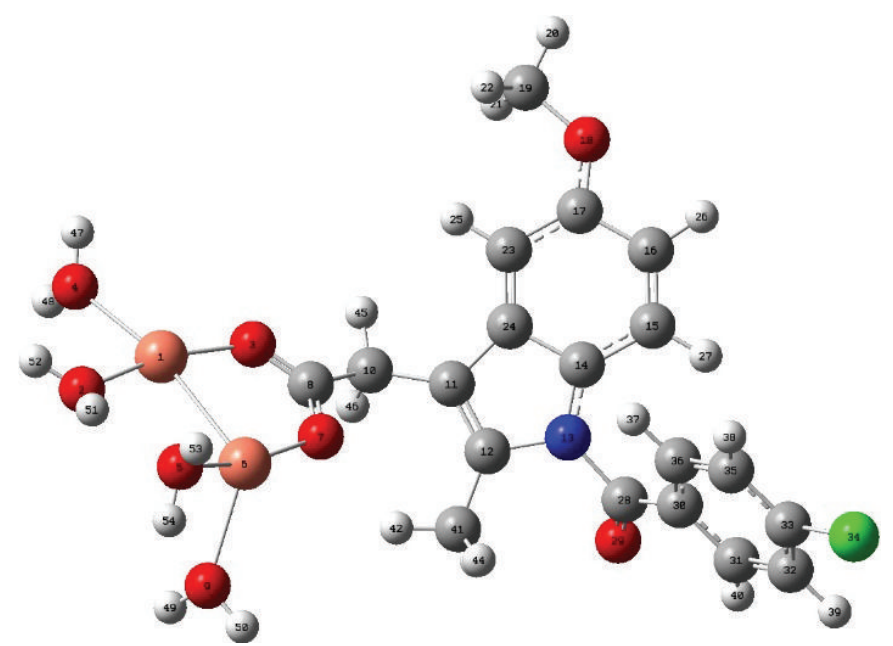

(b)

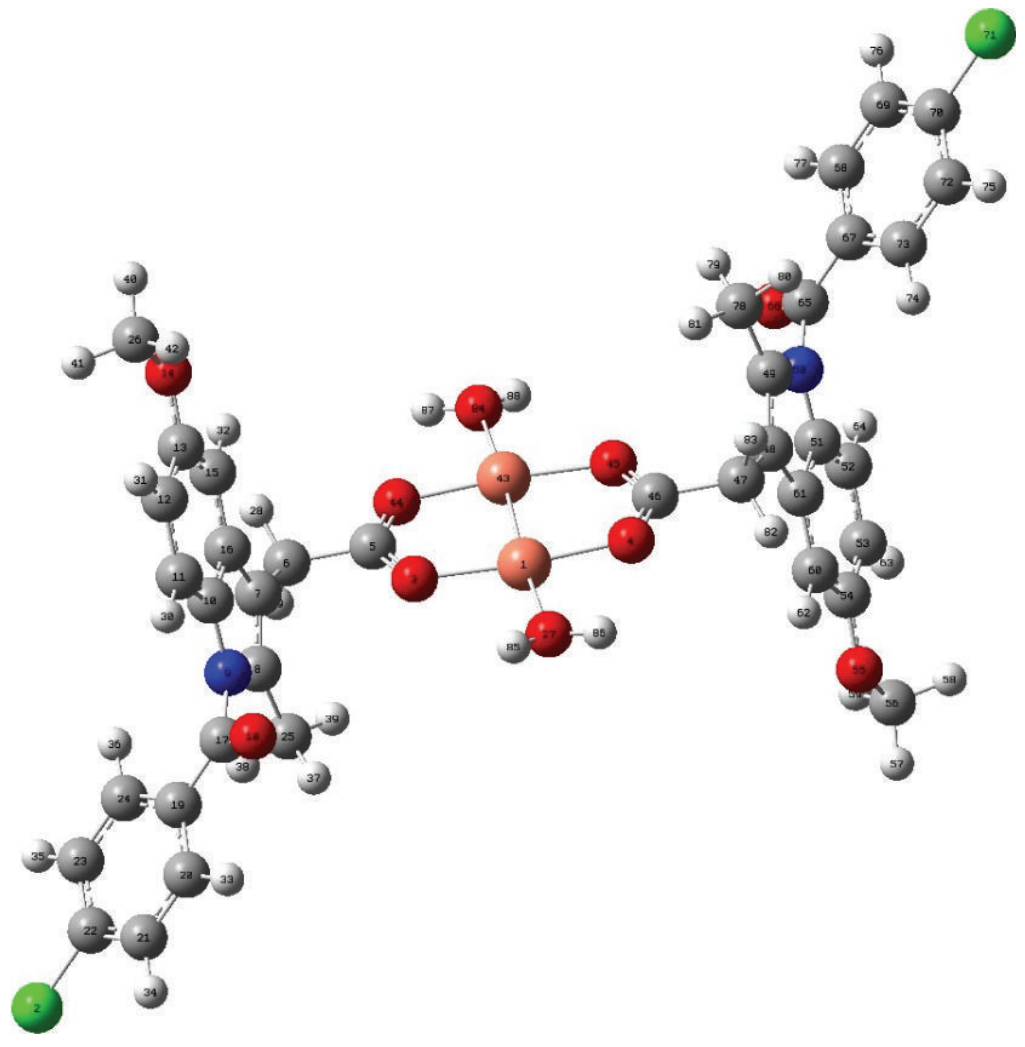

(c)

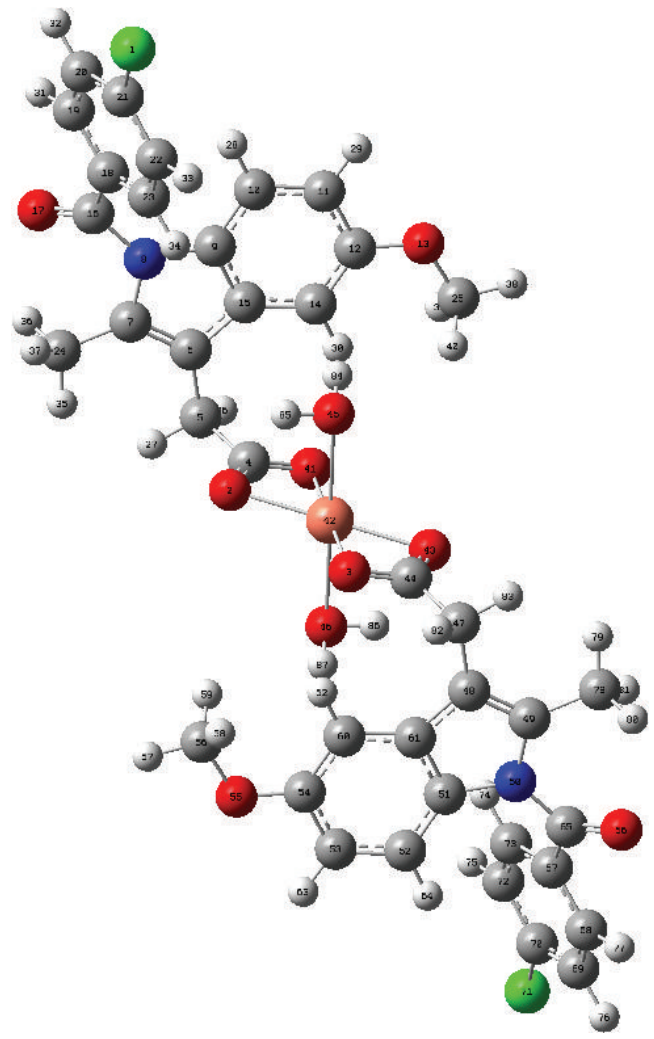

(d)

FIgURE 14: Determined molecular structures using theoretical methods for (a) CuIndo ${ }^{+}$, (b) $\mathrm{Cu}_{2} \mathrm{Indo}^{3+}$, (c) $\mathrm{Cu}_{2} \mathrm{Indo}_{2}{ }^{2+}$, and (d) $\mathrm{CuIndo}_{2}$.

The distances of $\mathrm{Cu}(\mathrm{II})-\mathrm{Cu}(\mathrm{II})$ complexes with stoichiometries $2: 1$ and $2: 2$ are $2.72 \AA$ and $2.51 \AA$, respectively, confirming the statement by Weder et al. [9]. Finally, the $1: 2$ complex was optimized with 2 water molecules to give place to the complex [CuIndo ${ }_{2}\left(\mathrm{H}_{2} \mathrm{O}\right)_{2}$ ], the average angle between the $\mathrm{O}-\mathrm{C}-\mathrm{O}$ atoms of the carboxylate of both Indomethacin groups is $119.03^{\circ}$, and the average angle between planes of both Indomethacin ligands is $56.58^{\circ}$. The molecular geometry of $\mathrm{Cu}(\mathrm{II})$ for this complex is octahedral (Figure 14(d)).

\section{Conclusions}

From the UV-Vis spectra and molar ratios and continuous variations methods, it was determined that the formed complexes between $\mathrm{Cu}(\mathrm{II})$ and Indomethacin have stoichiometric ratio $1: 1$ (in water) and $1: 2,2: 1$, and 2:2 (in ethanol); these complexes are CuIndo ${ }^{+}, \mathrm{CuIndo}_{2}, \mathrm{Cu}_{2} \mathrm{Indo}^{3+}$, and $\mathrm{Cu}_{2} \mathrm{Indo}_{2}{ }^{2+}$, respectively. The dimeric species of $\mathrm{Cu}(\mathrm{II})$ are formed for $\mathrm{Cu}$ (II) concentrations of $10^{-3} \mathrm{M}$ or higher. 
The $\mathrm{Cu}_{2} \mathrm{Indo}_{4}$ precipitates and was characterized by its X-ray powder diffraction patterns and its IR spectrum.

The values of the global formation constants $(\log \beta)$ obtained with SQUAD for the four identified complexes are $6.8345 \pm 0.0802,14.0552 \pm 0.4329,9.3790 \pm 0.0516$, and $16.7165 \pm 0.4419$, respectively. To accept and verify that these results are valid, theoretical absorption spectra with experimental spectra were compared; the observed overlap indicates a good fit between them, which supports the reproducibility of the experiment. To calculate the theoretical absorbance, the Beer-Lambert law and law of absorbance additivity were applied using molar absorptivity coefficients provided by SQUAD in their output and the molar fractions provided by MEDUSA which are used to determine the concentration of each species in the system.

Through the density functional theory (DFT), molecular geometries of the first solvation sphere of the complexes determined experimentally were proposed. To determine these structures, modeling was performed with water molecules in the first solvation sphere. It was determined that the atoms of $\mathrm{Cu}(\mathrm{II})$ in the complexes with stoichiometries $1: 1,2: 1$, and $2: 2$ are stable with a coordination number of 4 obtaining a square geometry, while, for the $1: 2$ complex, the atom of $\mathrm{Cu}(\mathrm{II})$ prefers a coordination number of 6 , acquiring an octahedral geometry. The chemical formula of each modeled complex between $\mathrm{Cu}$ (II) and Indomethacin is $\left[\mathrm{CuIndo}\left(\mathrm{H}_{2} \mathrm{O}\right)_{2}\right]^{+},\left[\mathrm{Cu}_{2} \operatorname{Indo}\left(\mathrm{H}_{2} \mathrm{O}\right)_{4}\right]^{3+}$, $\left[\mathrm{Cu}_{2} \operatorname{Indo}_{2}\left(\mathrm{H}_{2} \mathrm{O}\right)_{2}\right]^{2+}$, and $\left[\mathrm{CuIndo}_{2}\left(\mathrm{H}_{2} \mathrm{O}\right)_{2}\right]$.

\section{Competing Interests}

The authors declare that they have no competing interests.

\section{Acknowledgments}

Norma Rodríguez-Laguna wants to acknowledge DGAPAUNAM and IUM-FESC for the postdoctoral fellowship. Luis I. Reyes-García acknowledges CONACyT for the Ph.D. scholarship. The authors gratefully acknowledge the computing time provided by DGTIC-UNAM. This research was conducted under Grants PAPIIT DGAPA-UNAM IN222914 and PIAPI FESC-UNAM C23.

\section{References}

[1] J. Page and D. Henry, "Consumption of NSAIDs and the development of congestive heart failure in elderly patients: an underrecognized public health problem," Archives of Internal Medicine, vol. 160, no. 6, pp. 777-784, 2000.

[2] P. L. McGeer, M. Schulzer, and E. G. McGeer, "Arthritis and anti-inflammatory agents as possible protective factors for Alzheimer's disease: a review of 17 epidemiologic studies," Neurology, vol. 47, no. 2, pp. 425-432, 1996.

[3] K. Sugaya, T. Uz, V. Kumar, and H. Manev, "New anti-inflammatory treatment strategy in Alzheimer's disease," Japanese Journal of Pharmacology, vol. 82, no. 2, pp. 85-94, 2000.

[4] A. K. Jain, "Solubilization of indomethacin using hydrotropes for aqueous injection," European Journal of Pharmaceutics and Biopharmaceutics, vol. 68, no. 3, pp. 701-714, 2008.
[5] P. A. M. Williams, M. S. Molinuevo, N. Okulik, A. H. Jubert, and S. B. Etcheverry, "Synthesis, characterization and biological properties of vanadyl(IV) complexes of diclofenac and indomethacin: an experimental and theoretical study," Applied Organometallic Chemistry, vol. 19, no. 6, pp. 711-718, 2005.

[6] R. McNally, Drug Information for Health Care Professional (USPDI), vol. 1, Medical Economics Company, North Olmsted, Ohio, USA, 21st edition, 2001.

[7] S. Moncada and J. R. Vane, "Mode of action of aspirin-like drugs," Advances in Internal Medicine, no. 24, pp. 1-22, 1979.

[8] L. J. Marnett and A. S. Kalgutkar, "Cyclooxygenase 2 inhibitors: discovery, selectivity and the future," Trends in Pharmacological Sciences, vol. 20, no. 11, pp. 465-469, 1999.

[9] J. E. Weder, C. T. Dillon, T. W. Hambley et al., "Copper complexes of non-steroidal anti-inflammatory drugs: an opportunity yet to be realized," Coordination Chemistry Reviews, vol. 232, no. 1-2, pp. 95-126, 2002.

[10] J. Comer, S. Judge, D. Matthews et al., "The intrinsic aqueous solubility of indomethacin," ADMET \& DMPK, vol. 2, no. 1, pp. 18-32, 2014.

[11] F. Shakeel, F. K. Alanazi, I. A. Alsarra, and N. Haq, "Solubility prediction of indomethacin in PEG $400+$ water mixtures at various temperatures," Journal of Molecular Liquids, vol. 188, pp. 28-32, 2013.

[12] M. A. Soto, Estudio químico computacional de las propiedades ácido-base de la indometacina [thesis], Universidad Nacional Autónoma de México-Facultad de Estucios Superiores Cuautitlán, Mexico City, Mexico, 2010 (Spanish).

[13] M. C. Martínez, Determinación de las constantes de acidez del fármaco antiinflamatorio Indometacina [M.S. thesis], Universidad Nacional Autónoma de México-Facultad de Estucios Superiores Cuautitlán, Mexico City, Mexico, 2010 (Spanish).

[14] C. Ràfols, M. Rosés, and E. Bosch, "A comparison between different approaches to estimate the aqueous $\mathrm{p} K_{a}$ values of several non-steroidal anti-inflammatory drugs," Analytica Chimica Acta, vol. 338, no. 1-2, pp. 127-134, 1997.

[15] W. Bannister, "Copper and zinc inflammatory and degenerative diseases," Biochemical Education, vol. 27, no. 1, pp. 65-66, 1999.

[16] J. R. J. Sorenson, "Copper complexes offer a physiological approach to treatment of chronic diseases," Progress in Medicinal Chemistry, vol. 26, pp. 437-568, 1989.

[17] C. A. Tagliati, E. Kimura, M. S. Nothenberg, S. R. J. C. Santos, and S. Oga, "Pharmacokinetic profile and adverse gastric effect of zinc-piroxicam in rats," General Pharmacology, vol. 33, no. 1, pp. 67-71, 1999.

[18] G. Morgant, N.-H. Dung, J.-C. Daran et al., "Low-temperature crystal structures of Tetrakis- $\mu$-3,5- diisopropylsalicylatobisdimethylformamidodicopper(II) and Tetrakis- $\mu$-3,5- diisopropylsalicylatobis-diethyletheratodicopper(II) and their role in modulating polymorphonuclear leukocyte activity in overcoming seizures," Journal of Inorganic Biochemistry, vol. 81, no. 1-2, pp. 11-22, 2000.

[19] G. Morgant, B. Viossat, J.-C. Daran et al., "Crystal structure at $180^{\circ} \mathrm{K}$ of bis-3,5- diisopropylsalicylatobisdimethylsulfoxidozinc(II) and the inhibition of seizures and polymorphonuclear leukocyte chemiluminescence," Journal of Inorganic Biochemistry, vol. 70, no. 2, pp. 137-143, 1998.

[20] F. Guessous, J.-C. Daran, B. Viossat et al., “Ternary copper(II) complexes with indomethacin, a potent non-steroidal antiinflammatory drug. Crystal structure of bis (dimethylformamide)-tetrakis[1-(4-chlorobenzoyl)-5-methoxy-2-methyl-1- $H$ indole-3-acetato]dicopper(II). Antiinflammatory properties 
and prevention of gastrointestinal side effects by nanocapsules," Metal-Based Drugs, vol. 5, no. 6, pp. 337-345, 1998.

[21] J. E. Weder, T. W. Hambley, B. J. Kennedy et al., "Anti-inflammatory dinuclear copper(ii) complexes with indomethacin. synthesis, magnetism and EPR spectroscopy. Crystal structure of the N,N-dimethylformamide adduct," Inorganic Chemistry, vol. 38, no. 8, pp. 1736-1744, 1999.

[22] U. Weser, K. H. Sellinger, E. Lengfelder, W. Werner, and J. Strähle, "Structure of $\mathrm{Cu} 2$ (Indomethacin) 4 and the reaction with superoxide in aprotic systems," Biochimica et Biophysica Acta, vol. 631, no. 2, pp. 232-245, 1980.

[23] C. T. Dillon, T. W. Hambley, B. J. Kennedy, P. A. Lay, J. E. Weder, and Q. Zhou, Copper and Zinc Complexes as Antiinflammatory Drugs, Centre for Heavy Metals Research, School of Chemistry, University of Sydney, Sydney, Australia, 2006.

[24] M. Melník, "Mono-, bi-, tetra- and polynuclear copper(II) halogenocarboxylates," Coordination Chemistry Reviews, vol. 36, no. 1, pp. 1-44, 1981.

[25] S. J. Jenniefer and P. T. Muthiah, "Synthesis, characterization and X-ray structural studies of four copper (II) complexes containing dinuclear paddle wheel structures," Chemistry Central Journal, vol. 7, no. 1, article 35, 15 pages, 2013.

[26] A. Rojas-Hernández, N. Rodríguez-Laguna, M. T. RamírezSilva, and R. Moya-Hernández, "Distribution diagrams and graphical methods to determine or to use the stoichiometric coefficients of acid-base and complexation reactions," in Stoichiometry and Research: The Importance of Quantity in Biomedicin, A. Innocenti, Ed., chapter 13, pp. 287-310, InTech, Rijeka, Croatia, 2012.

[27] R. Moya-Hernández, R. Gómez-Balderas, A. Mederos, S. Domínguez, M. T. Ramírez-Silva, and A. Rojas-Hernández, "Complex formation of the anti-inflammatory drugs tenoxicam and piroxicam with $\mathrm{Fe}$ (III) in methanol and acetone," Journal of Coordination Chemistry, vol. 62, no. 1, pp. 40-51, 2009.

[28] A. Castañeda-Ovando, C. A. Galán-Vidal, E. Contreras-López, and M. E. Páez-Hernández, "Purification of anthocyanins with o-dihydroxy arrangement by sorption in cationic resins charged with Fe(III)," Journal of Chemistry, vol. 2014, Article ID 367236, 9 pages, 2014.

[29] D. J. Leggett and W. A. E. McBryde, "General computer program for the computation of stability constants from absorbance data," Analytical Chemistry, vol. 47, no. 7, pp. 1065-1070, 1975.

[30] I. Puigdomenech, Making Equilibrium Diagrams Using Sophisticated Algorithms (MEDUSA), Software, https://www.kth.se/ en/che/medusa/downloads-1.386254.

[31] F. R. Hartley, C. Burguess, and R. M. Alcock, Solution Equilibria, E. Horwood, Chichester, UK, 1980.

[32] P. Job, "Formation and stability of inorganic complexes in solution," Annales de Chimie-Paris, no. 9, pp. 113-203, 1928.

[33] M. J. Frisch, G. W. Trucks, H. B. Schlegel et al., Gaussian 03, B1, Gaussian, Pittsburgh, Pa, USA, 2003.

[34] S. F. Sousa, P. A. Fernandes, and M. J. Ramos, "General performance of density functionals," Journal of Physical Chemistry A, vol. 111, no. 42, pp. 10439-10452, 2007.

[35] F. Weigend and R. Ahlrichs, "Balanced basis sets of split valence, triple zeta valence and quadruple zeta valence quality for $\mathrm{H}$ to Rn: design and assessment of accuracy," Physical Chemistry Chemical Physics, vol. 7, no. 18, pp. 3297-3305, 2005.

[36] A. Schäfer, C. Huber, and R. Ahlrichs, "Fully optimized contracted Gaussian basis sets of triple zeta valence quality for atoms Li to Kr," The Journal of Chemical Physics, vol. 100, no. 8, pp. 5829-5835, 1994.
[37] M. Kyuzou, W. Mori, and J. Tanaka, "Electronic structure and spectra of cupric acetate mono-hydrate revisited," Inorganica Chimica Acta, vol. 363, no. 5, pp. 930-934, 2010.

[38] I. Monte-Pérez, A. M. Sosa, S. Bernès, N. Aliaga-Alcalde, V. M. Ugalde-Saldívar, and L. Gasque, " $\mathrm{pH}$-dependent imidazolato bridge formation in dicopper complexes: magnetic, electrochemical, and catalytic repercussions," European Journal of Inorganic Chemistry, no. 29, pp. 4739-4749, 2012.

[39] M. R. Mendoza-Quijano, G. Ferrer-Sueta, M. Flores-Álamo et al., "Mechanistic insight on the catecholase activity of dinuclear copper complexes with distant metal centers," Dalton Transactions, vol. 41, no. 16, pp. 4985-4997, 2012. 

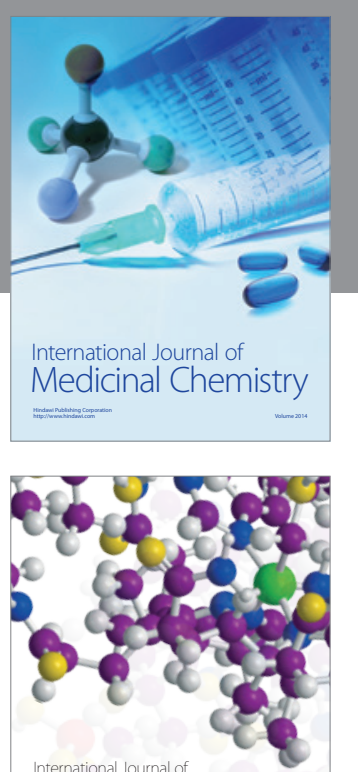

Carbohydrate Chemistry

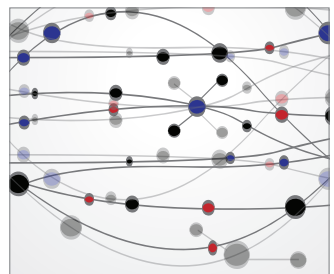

The Scientific World Journal
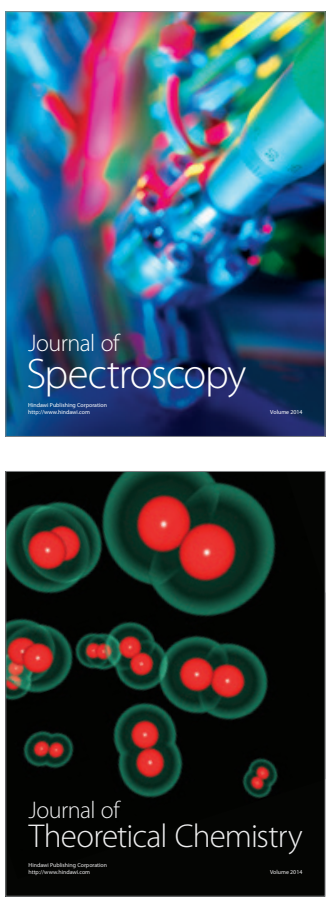
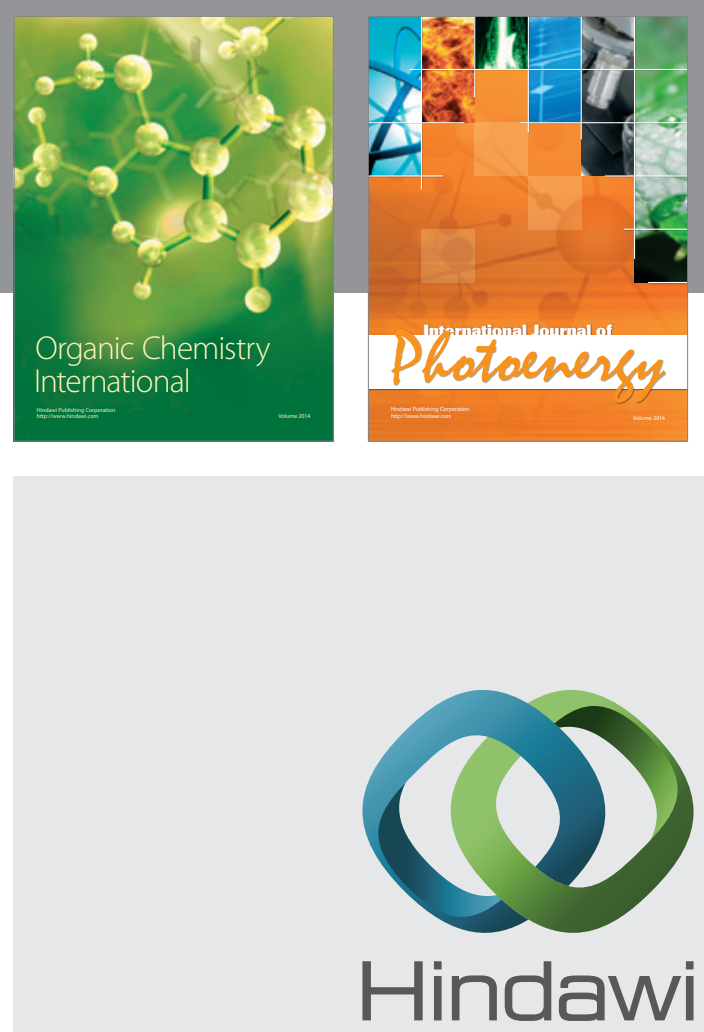

Submit your manuscripts at

http://www.hindawi.com

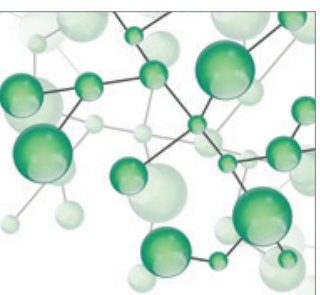

International Journal of

Inorganic Chemistry

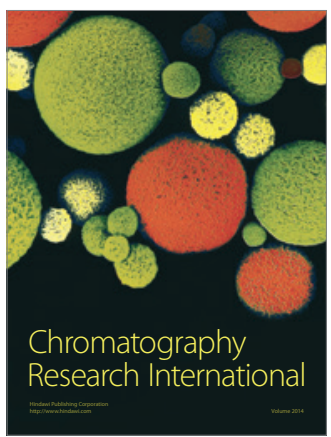

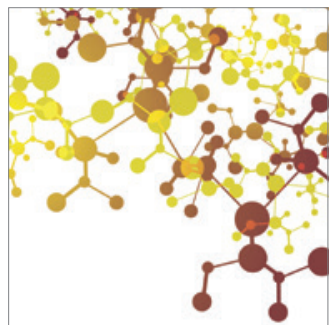

Applied Chemistry
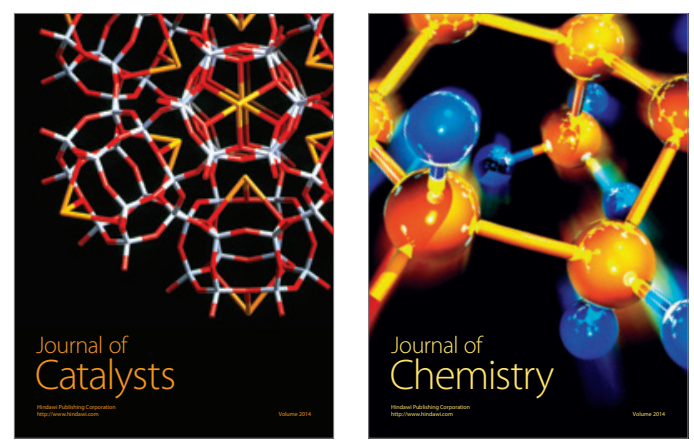
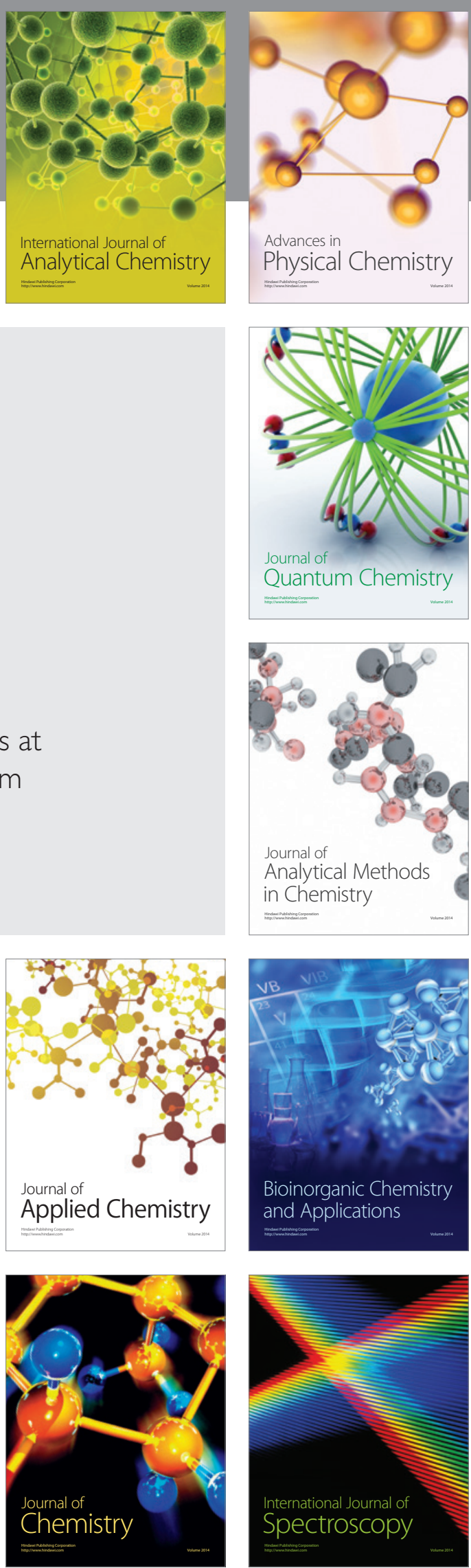